\title{
Antifascismo: un espacio de encuentro entre el exilio y la política nacional. El caso de Vicente Lombardo Toledano en México (1936-1945)
}

\author{
por \\ Andrea Acle-Kreysing* \\ Ludwig-Maximilians-Universität Munich/Universität Leipzig \\ andrea.acle-kreysing@uni-leipzig.de
}

Este artículo propone una lectura original del antifascismo, entendido como una cultura política trasatlántica, a partir del caso del líder sindicalista Vicente Lombardo Toledano. Se discute la evolución del significado del antifascismo en México, centrado en la recreación del legado de la Revolución Mexicana, en el período comprendido entre la Guerra Civil española y la Segunda Guerra Mundial, enfatizando la colaboración entre el exilio antifascista europeo y los círculos izquierdistas locales. A partir de varios documentos inéditos, se reivindica el protagonismo que México ejerció entonces en virtud de su compromiso ideológico.

Palabras clave: antifascismo; México; Vicente Lombardo Toledano; Segunda Guerra Mundial; antisemitismo; exilio alemán.

La falta de coherencia ideológica es, paradójicamente, una de las grandes virtudes del antifascismo. Me refiero a la capacidad de propiciar el acercamiento coyuntural de distintas agendas políticas, así como de movilizar a diversos

* Agradezco a Xosé Manoel Núñez Seixas (Ludwig-Maximilians-Universität) por sus valiosos comentarios, así como a Enrique Gutiérrez de la Cruz y sus colaboradores (Fondo Histórico Vicente Lombardo Toledano, Ciudad de México) por su ayuda en la búsqueda de documentos. Este artículo es parte de un proyecto financiado por la Fundación Alexander von Humboldt y tuvo su origen en una ponencia presentada en las XIV Jornadas Interescuelas de Historia en Mendoza, Argentina (octubre 2013). 
actores más allá de la extrema izquierda ${ }^{1}$. De ahí la importancia de comprender al antifascismo como un movimiento en perpetua definición y observar cómo, desde su maleabilidad, pudo convertirse en una justificación para convertir al exilio, entendido como la voluntad de acoger a aquellos perseguidos por el fascismo, en un tema de política nacional. En el caso de México, durante el período comprendido entre las presidencias de Lázaro Cárdenas (1934-1940) y Manuel Ávila Camacho (1940-1946), es posible advertir un cambio significativo en las acepciones prevalecientes del término antifascismo. En términos generales, éste fue inicialmente utilizado como herramienta para lograr un cambio radical, a partir de la relectura -bajo una óptica comunista- de los postulados de la Revolución Mexicana (1910-1917), convirtiéndose después en expresión de la voluntad de México de alinearse con Estados Unidos durante la Segunda Guerra Mundial, privilegiando la unidad nacional por encima de la transformación de la sociedad. En este proceso, la influencia ideológica ejercida por distintos grupos de izquierda fue gradualmente reemplazada por la eficiente propaganda de los Aliados, cuya interpretación de la guerra terminó por prevalecer en los medios de comunicación mexicanos ${ }^{2}$. Prescindiendo de este viraje, el compromiso antifascista de México tuvo siempre una orientación práctica, puesto que la imagen internacional del país se suponía ligada a metas nacionales, ya sea mediante el posicionamiento del país en la vanguardia progresista o, más tarde, en la lucha llevada a cabo por los países occidentales en pro de la democracia.

Pocas figuras dan mejor cuenta de los avatares del antifascismo en México que la del líder obrero Vicente Lombardo Toledano (1894-1968). En este trabajo, se analizará el carácter de Lombardo como teórico mexicano del antifascismo, dado su esfuerzo en definir el significado de la lucha antifascista en los años treinta y cuarenta desde una variedad de foros y registros: en mítines multitudinarios y artículos de fondo, más contactos personales con intelectuales europeos y latinoamericanos. La ayuda de Lombardo, reflejada en amplias movilizaciones obreras, fue crucial para que el presidente Cárdenas llevara a cabo su política de apoyo constante a la República Española y, después de la victoria de Franco, de acogida al exilio republicano español. Si bien la posición de Lombardo se situó claramente dentro de la izquierda marxista, llama la atención que mantuviera una relación ambigua respecto del Partido Comunista, del cual fue simpatizante y no miembro propiamente dicho. Sin embargo, congruente con la línea de este partido, se opuso férreamente a la recepción en México del célebre exiliado León Trotsky. Durante la presi-

\footnotetext{
${ }^{1}$ Rabinbach, 2009: 184.

${ }^{2}$ Schuler, 1998: 148-150.
} 
dencia de Ávila Camacho, Lombardo apoyó decididamente las actividades en México del exilio antifascista de habla alemana, en particular del movimiento «Alemania Libre» (Bewegung Freies Deutschland), de inspiración comunista. Aquí también puede subrayarse el interés de Lombardo en integrar a distintas personalidades del exilio antifascista en instituciones a su cargo tales como la Universidad Obrera, cuya oferta educativa estaba específicamente dirigida a los trabajadores, así como en la revista Futuro. A ello se sumaron los empeños de Lombardo en convertir al antifascismo en uno de los pilares ideológicos del movimiento obrero latinoamericano, en cuanto dirigente de la Confederación de Trabajadores de América Latina (CTAL).

El objetivo de este artículo es tratar de comprender cuáles fueron los discursos políticos que hicieron posible imaginar una lucha común entre exiliados europeos antifascistas e intelectuales y políticos latinoamericanos, haciendo del antifascismo una cultura política capaz de influir en audiencias a ambos lados del Atlántico. Por un lado, me interesa destacar en qué medida, al encontrarse en un contexto inédito, los exiliados políticamente comprometidos ampliaron el significado original (esto es, europeo) de la lucha antifascista ante la necesidad de reconstruir su audiencia y bases de apoyo, en aras de llevar a cabo una campaña efectiva en contra de Hitler, Mussolini y Franco. Por el otro, pienso resaltar cómo el conflicto entre fascismo y antifascismo se convirtió en un marco de referencia para los intelectuales y políticos latinoamericanos, esto es, en un vocabulario que permitió que la problemática local adquiriera un sentido más amplio, incluso universal. Según Pasolini, el antifascismo no sólo fue una "sensibilidad ideológica» capaz de transformarse en fuerza de resistencia, sino que dio lugar a una «mise en scène» de los problemas internos de los países afectados, aun de forma tangencial como México, puesto que la amenaza fascista - real o imaginada- se convirtió en un acicate para las tradiciones políticas locales, obligándolas a repensar su «proyección de futuro» ${ }^{3}$.

En los años treinta y tras la experiencia de la Guerra Civil Española, el ascenso del nazismo al poder convirtió lo que había sido «un problema esencialmente italiano, en una amenaza real para la paz en Europa $\rangle^{4}$. El antifascismo se trocó así en el «común denominador» de sensibilidades políticas muy variadas que, si bien luchaban en contra de un mismo enemigo, representaban visiones de futuro distintas. La «voluntad de transformación social» propia del antifascismo, lejos de ser exclusiva del partido comunista o el movimiento obrero, conoció otras variantes: anarquista, socialista, cató-

\footnotetext{
3 Pasolini, 1998: 48.

4 Groppo, 2007: 106-109.
} 
lica o liberal-democrática ${ }^{5}$. Esta insistencia en la pluralidad de la experiencia antifascista contrasta con la lectura que autores como François Furet han hecho del antifascismo, considerado como una ideología instrumentalizada por los partidos comunistas en beneficio de la Unión Soviética e incluso como un intento de desviar la atención de los crímenes del estalinismo hacia los del nazismo, aunque es innegable que defender la democracia bajo amenaza del fascismo y, al mismo tiempo, celebrar a la Unión Soviética cuando el terror estaba en su apogeo, supuso una gran contradicción ${ }^{6}$. Sin embargo, la retórica maniquea del antifascismo, la cual reclamaba una elección urgente entre alternativas fundamentales (por ejemplo, civilización versus barbarie), constituyó una especie de «bono moral» que frecuentemente hizo que aquél permaneciera inmune a las contradicciones, comenzando por el pacto entre Hitler y Stalin, y los excesos de comunistas, soviéticos o no ${ }^{7}$. Al fin de la Segunda Guerra Mundial, el antifascismo sirvió como mito fundador, en sus variantes del Frente Popular y de la Resistencia, para los regímenes de la posguerra y, en particular, como justificación ideológica de las dictaduras de Europa del Este, más el caso paradigmático de Alemania Oriental.

En el caso de México, el significado del antifascismo fue construyéndose a partir de la interacción entre las circunstancias locales y las europeas. Su legado más perdurable fue la «recreación» de la Revolución Mexicana (1910-1917), a manos de distintos círculos izquierdistas durante los años treinta y cuarenta, de manera que lo que fue originalmente una guerra civil se interpretó ahora como un conflicto patriótico en pro de la liberación y transformación nacional. La puesta al día de la Revolución sirvió así para justificar el ascenso de nuevos actores sociales, comenzando por el movimiento obrero, y para hacer un renovado énfasis en la necesidad que México tenía de un mayor grado de democracia, entendida sobre todo como una redistribución de recursos. Estas ideas fueron formuladas de manera emblemática por Hernán Laborde, secretario general del Partido Comunista Mexicano, quien se refirió a la Revolución Mexicana como un proceso inconcluso, puesto que los obstáculos que se oponían al progreso del país todavía debían allanarse: el atraso económico y cultural, así como la concentración de los medios de producción en unas cuantas manos ${ }^{8}$. Para los círculos izquierdistas en México, el marxismo fue visto como el vehículo idóneo para llevar finalmente a cabo la Revolución, esto es, para continuarla y hacerla realidad.

\footnotetext{
${ }^{5}$ Ibidem: 96-97.

${ }^{6}$ Ibidem: 111, 114.

${ }^{7}$ Rabinbach, 1996: 5, 9.

${ }^{8}$ Laborde, 1938: 10.
} 
Esta puesta al día -en clave antifascista- de la propia Revolución Mexicana se asemeja al desarrollo que tuvo lugar en el contexto de la Guerra Civil Española, esto es, la reconciliación entre comunismo y nacionalismo, una vez que el Partido Comunista se viera obligado a abrazar la temática nacionalista como estrategia para incrementar su influencia y facilitar la movilización en tiempos de guerra ${ }^{9}$. Según Núñez y Faraldo, los comunistas españoles se valieron del recurso al patriotismo como motivo revolucionario y dieron lugar a la idea de que no se trataba de una guerra civil sino de una lucha en contra de un invasor externo que, en todo caso, se valía de aliados locales. Esto explica que, en los círculos pro-comunistas asociados a Lombardo, haya persistido el intento de vincular a la Revolución Mexicana y a la República Española en una lucha común, la cual debía librarse en un escenario mucho más amplio que el propio país. Actuando como puente entre causas nacionales e internacionales, el discurso antifascista tuvo además su propia estética, expresada plásticamente en las obras de los miembros de la Liga de Escritores y Artistas Revolucionarios (1934-1937) y posteriormente del Taller de Gráfica Popular, fundado en 1937. Además de llevar a cabo una recreación visual de la propia Revolución, el Taller se involucró desde un principio en la denuncia abierta del fascismo europeo, como reflejaron sus primeros trabajos en pro de la República española. Más tarde, este compromiso antifascista fue reforzado cuando dos exiliados germano-hablantes de simpatías comunistas, Hannes Mayer y Georg Stibi, tomaron a su cargo la dirección del Taller (1942-1946).

La nota distintiva del antifascismo mexicano, especialmente en el círculo de Lombardo Toledano, fue haberle apostado a una fuerte colaboración con el Estado post-revolucionario. En consecuencia, la izquierda brindó su autoridad moral al Estado, confirmando las pretensiones de éste de ser el intérprete privilegiado de la nación y el nacionalismo ${ }^{10}$. Durante el sexenio de Cárdenas, la alianza entre amplios sectores de la izquierda y el Estado cosechó grandes frutos, comenzando por el apoyo abierto a la República Española, sólo comparable al que fue brindado a ésta por la Unión Soviética. Por lo demás, esta alianza estuvo sujeta a la interacción problemática entre las distintas vertientes de la izquierda: el llamado «lombardismo», el propio Partido Comunista Mexicano y grupos trotskistas, entre otros. Cabe añadir que éstas fueron alternativas que no pudieron sustraerse a la creciente importancia del partido oficial, supuesto representante de todas las clases y movimientos sociales.

Pero el gobierno de Cárdenas fue el canto del cisne del llamado «reformismo revolucionario»: por un lado, el énfasis en la justicia social se desvaneció,

\footnotetext{
9 Núñez y Faraldo, 2009: 401-403.

10 Carr, 1994: 327, 347.
} 
no obstante la supervivencia de la retórica populista; por el otro, sobre todo tras la Segunda Guerra Mundial, se abandonó la postura anti-imperialista y de confrontación con Estados Unidos ${ }^{11}$. Ello tuvo un impacto indudable en la influencia social y política ejercida por la izquierda e incluso por el propio Lombardo quien, en menos de dos décadas, pasó de ser una figura crucial a una marginal. Respecto de la propia campaña antifascista, poco a poco, los compromisos políticos puntuales - por ejemplo, una posición pro-Aliados- fueron cobrando mayor importancia que los objetivos más ambiciosos, orientados a la renovación de las estructuras sociales.

Importa destacar que la prevalencia del nacionalismo revolucionario que, por lo menos hasta la década de los ochenta sirvió como una especie de ideología oficial en México $^{12}$, ha tendido a opacar las distintas corrientes ideológicas que confluyeron en él, en este caso, el antifascismo de inspiración marxista. Lejos de ser un discurso monolítico, el nacionalismo revolucionario mostró una capacidad notable para incorporar demandas provenientes tanto de la derecha como de la izquierda aunque, a largo plazo, perdiera su verosimilitud ${ }^{13}$. Tanto la maleabilidad ideológica como la invocación constante de la Revolución Mexicana como justificación tanto de proyectos políticos como de políticas públicas, son elementos que hicieron al nacionalismo revolucionario compatible con el antifascismo. Otras características de la cultura política del México post-revolucionario que tuvieron un impacto indudable en el esfuerzo antifascista fueron, por un lado, la propensión a preferir las alianzas pactadas por encima del libre juego de las fuerzas políticas y, por el otro, el esfuerzo por transformar alianzas coyunturales en acciones prácticas, a través de instituciones, publicaciones, comités, etc.

Por último, habría que añadir que la alianza entre Estado e izquierda durante la década de los treinta y cuarenta, al menos en lo que se refiere a Lombardo y al movimiento obrero, no sólo fue una fatalidad del destino, sino también una consecuencia del diseño institucional del México post-revolucionario. En la Constitución de 1917, que designó al Estado como árbitro de los conflictos entre empresarios y obreros, quedó cimentado el carácter que tendrían las relaciones laborales en México. De ahí que lograr la «conquista del Estado», con el objeto de inclinar la balanza a su favor, se convirtiera en una tarea central para los sindicatos, al precio de incrementar su dependencia

${ }^{11}$ Meyer, 2010: 52-53.

12 Idem. Ésta se caracterizó por tres elementos básicos: el énfasis en las políticas sociales, la ampliación de la independencia relativa de México frente a Estados Unidos y la existencia de un partido de Estado con bases corporativas.

${ }^{13}$ Cárdenas y Tenorio, 2011: 608-609. 
respecto del propio Estado ${ }^{14}$. Así que, en un lapso de tiempo relativamente corto, Lombardo perdió su capacidad de acción independiente respecto del Estado y del partido oficial. Como se verá a lo largo de este artículo, esto constituyó un obstáculo para que la campaña antifascista en México alcanzara el objetivo último de todo antifascismo: influir en la construcción del mundo de la posguerra.

\section{El antifascismo durante el CARDENismo: Debates en torno a Trotsky}

El advenimiento de Lázaro Cárdenas al poder (1934-1940) ofreció la oportunidad única, con las luces y sombras del caso, de llevar a cabo varios de los postulados revolucionarios que habían permanecido latentes hasta entonces en la Constitución de 1917, relativos a la reforma agraria, al otorgamiento de mayores derechos para los trabajadores y a la nacionalización de los bienes del subsuelo. Las medidas de Cárdenas recibieron el calificativo de «anticlericales» y «bolcheviques» por parte de sus opositores, aunque más bien prodrían denominarse populistas, al estar centradas en la redistribución de la riqueza y en la reivindicación de grupos marginados ${ }^{15}$. Durante su presidencia, los movimientos campesino y obrero fueron incorporados al partido oficial, el Partido Nacional Revolucionario de la Revolución Mexicana a partir de 1938 y finalmente de la Revolución Institucional (PRI) desde 1946. El apoyo de estos grupos, así como de figuras destacadas de la élite política e intelectual, permitió a Cárdenas llevar adelante su programa de reformas, a pesar de la oposición significativa por parte de grupos de derecha radical, especialmente de aquellos que -no obstante su posición minoritaria- enarbolaban una retórica agresiva basada en el antisemitismo, el anticomunismo y el nacionalismo xenófobo, tales como la Unión Nacional Sinarquista, la Confederación de Clase Media, la Unión Pro-Raza y Acción Mexicanista Revolucionaria ${ }^{16}$. Al mismo tiempo, los años de Cárdenas fueron años de esplendor para el Partido Comunista Mexicano que, no sólo salió de la ilegalidad, sino que alcanzó el mayor número de miembros ${ }^{17}$.

Entre Cárdenas y Lombardo se estableció «una relación de apoyo mutuo» que no estuvo exenta de tensiones, debidas tanto a motivos prácticos como

\footnotetext{
14 Maihold, 2002: 28.

15 Knight, 1998: 223-224.

16 Mentz et al., 1984: 73.

${ }^{17}$ Carr, 1994: 329. Entre 35.000 y 40.000, respecto de un promedio de 10.000 .
} 
ideológicos ${ }^{18}$. Cuando Cárdenas subió al poder, el apoyo de Lombardo -entonces el líder sindical de mayor relieve- fue crucial para que aquél se sobrepusiera al ex presidente Plutarco Elías Calles y pudiera consolidarse en el poder. En 1936, Cárdenas facilitó la fundación de la Confederación de Trabajadores de México (CTM), a cargo de Lombardo, y apoyó su trayectoria internacional, a partir de la creación de la Confederación de Trabajadores de América Latina (CTAL) en septiembre de 1938. En toda América Latina, la incorporación de los obreros mediante mecanismos populistas y corporativistas de control, obedeció a que aquéllos se convirtieron entonces en «aliados de gobiernos que -desde un enfoque populista, popular o autoritario- quisieron imponerse a las oligarquías agrarias que defendían el viejo modelo agro-exportador de crecimiento ${ }^{19}$. Según Lombardo, para alcanzar el crecimiento económico nacionalista de México, basado en el fortalecimiento del mercado interno, era indispensable que el movimiento obrero se aliara con el poder público. Por tanto, desde las cúspides de la CTM y la CTAL, Lombardo cultivó un perfil de «intermediario ideal entre las masas y las instancias del poder», en sintonía con el carácter personalista del presidencialismo mexicano ${ }^{20}$.

Ello explica la afinidad que Lombardo sintió por la política de frentes populares adoptada en agosto de 1935 por la III Internacional Comunista, la cual supuso la formación de alianzas interclasistas para resistir el avance del fascismo. Justo entonces, Lombardo y su amigo Víctor Manuel Villaseñor se encontraban en la Unión Soviética en un viaje facilitado por el poeta español Rafael Alberti y su esposa, la escritora María Teresa León, comunistas y defensores de la República Española, de visita en México en mayo de 1935. Este viaje dio lugar a un interesante quid pro quo: mientras que la Comintern esperaba ganar a Lombardo para el comunismo, éste quería verse reconocido como el líder obrero indiscutible de México, lo cual le permitiría contar con el apoyo comunista antes de llamar a la creación de la $\mathrm{CTM}^{21}$. Escribiendo desde Moscú, Lombardo celebró que la Internacional Comunista dejara de lado el «método universal e invariable para todos los países» para adoptar en cambio «procedimientos elásticos, flexibles, de acuerdo con la realidad económica y política de cada región del mundo ${ }^{22}$. De regreso en México, Lombardo dio conferencias y publicó artículos sobre su viaje a la URSS. En ellos exaltó el

${ }^{18}$ Spenser, 2009: 4.

19 Ibidem: 5-6.

${ }^{20}$ Crespo, 2012: 7, 13.

${ }^{21}$ Spenser, 2010: 83-84.

${ }^{22}$ El VII Congreso de la Internacional Comunista, Moscú, VIII-1935, por Vicente Lombardo Toledano, Fondo Histórico Vicente Lombardo Toledano, México DF (FHVLT), leg. 266, id. 15620. 
bienestar de la población soviética, visto como prueba de que el socialismo conducía a la democracia y a la paz, en contraste con lo que él consideraba como consecuencias del capitalismo: crisis económica, fascismo y guerra ${ }^{23}$.

Estas convicciones llevarían a Lombardo a disentir de la decisión tomada por Cárdenas, en diciembre de 1936, de dar acogida en México a León Trotsky, el máximo opositor desde la izquierda al régimen de Stalin. Tanto el Partido Comunista Mexicano (PCM) como la CTM expresaron su desacuerdo, articulado de forma efectiva por Lombardo, quien interpretó el caso Trotsky a la luz de la historia mexicana ${ }^{24}$. Tras aclarar que no era comunista, Lombardo aplaudió que en México hubiera una discusión sobre el derecho de asilo, inseparable de un régimen democrático. Pero añadió que había una «relación íntima» entre este derecho y el artículo 33 de la Constitución, pues permitía al Presidente expulsar a quienes obraran en contra de la «paz pública». Tal había sido el caso, recientemente, del ex-presidente Calles y de Luis N. Morones, líder corrupto de la otrora central sindical, la Confederación Regional de Obreros de México (CROM). Según Lombardo -y aquí la referencia a Trotsky era impecablemente sutil- estos dos personajes lo tenían bien merecido, en cuanto se habían convertido en «prevaricadores de la revolución [mexicana]». Esta revolución, en opinión de Lombardo, había sido un Frente Popular avant la lettre, mucho antes de que la Internacional acuñara el término, puesto que había unido a obreros y campesinos con la clase media y la pequeña burguesía. ¿Cuál era la amenaza que Trotsky representaba para México? Según Lombardo, al oponerse a la táctica de frente popular y exigir que el proletariado se mantuviera en lucha contra gobiernos burgueses, el trotskismo atentaba contra el «programa» de la Revolución Mexicana. En aras de cumplir los «anhelos insatisfechos» del pueblo de México, este programa descansaba sobre dos bases: «la vinculación transitoria del proletariado y de otros sectores del pueblo con el Gobierno» y el monopolio legítimo de los derechos cívicos por parte del partido oficial. Romper esta alianza y provocar la disensión entre grupos populares, concluía su argumento, abriría la puerta al fascismo.

La presencia de Trotsky en México, que terminó con su asesinato en agosto de 1940, puso en especial evidencia las pugnas que existían en el seno de la izquierda, no sólo mexicana sino también internacional. A principios de 1937, Trotsky llegó a México gracias a la mediación del pintor Diego Rivera, cuya relevancia y contactos en el gobierno fueron a la postre más efectivos que la organización trotskista a la que Rivera pertenecía, la cual tenía una capacidad mínima de influencia. En los años siguientes, el rechazo a Trots-

\footnotetext{
${ }^{23}$ Spenser, 2010: 92.

${ }^{24}$ Lombardo Toledano, 1937: 9-11.
} 
IluStración 1. SANTOS BALMORI, TROTSKY, COMO REALMENTE ES

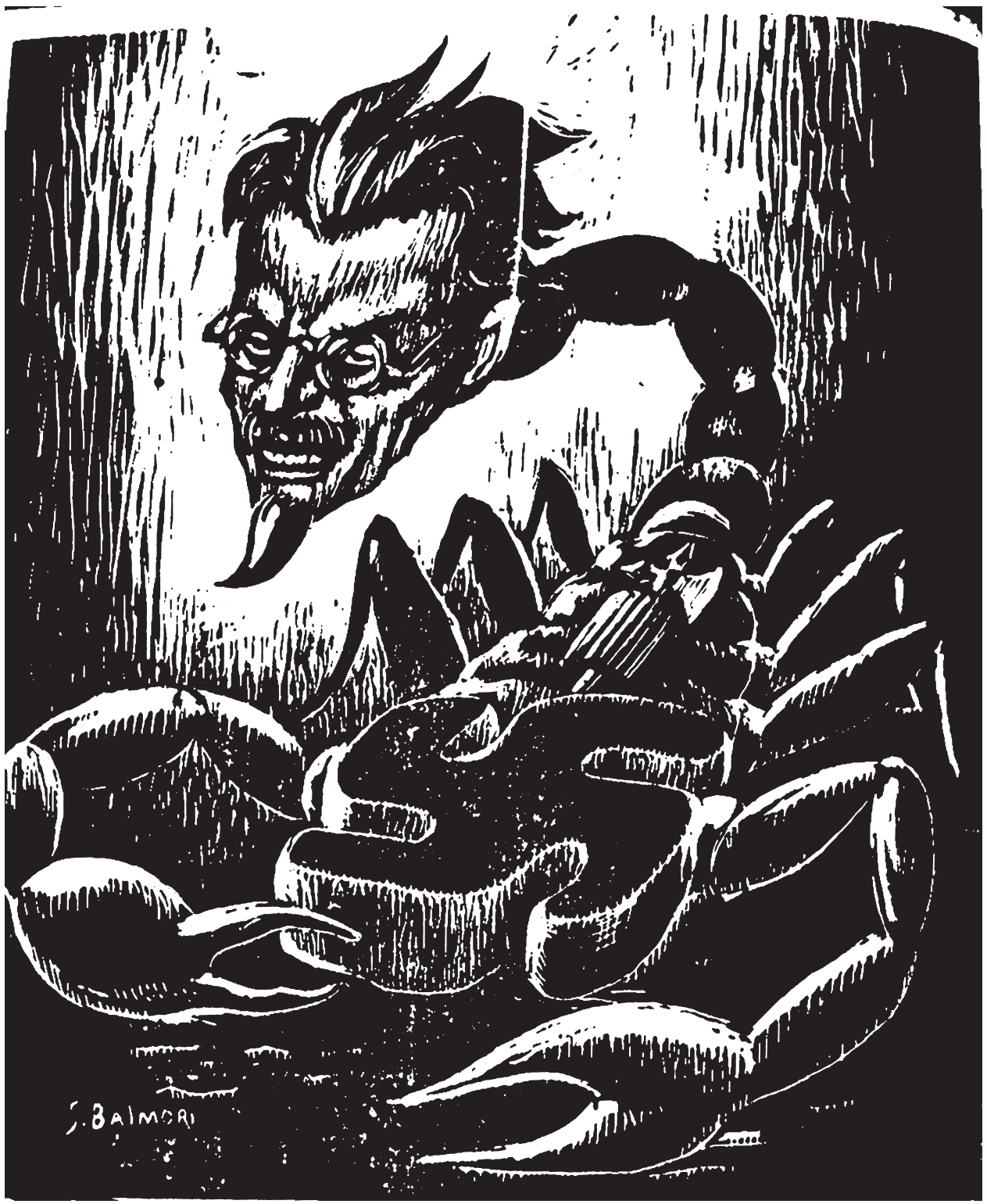

Fuente: Futuro, 3a época/34 (México, diciembre de 1938). 
ky subió de tono: en febrero de 1938, el II Congreso de la CTM le declaró «enemigo de México» y exigió su expulsión; en la segunda mitad de 1939, luego de que Hitler y Stalin firmaran un pacto de no agresión, Trotsky dejó de ser vinculado al nazismo y fue acusado de ser «agente del imperialismo yanqui»; y, en mayo de 1940, sufrió un atentado organizado por militantes del PCM y ex combatientes de la Guerra Civil española. El propio Trotsky acusó a Lombardo de estar detrás del atentado, tomando en cuenta de que uno de los involucrados -el comunista italiano Vittorio Vidali- trabajaba entonces en la redacción de El Popular, órgano informativo de la $\mathrm{CTM}^{25}$. Prescindiendo de la verdad de estas acusaciones, importa destacar cómo las disensiones ideológicas tiñeron la percepción respecto de la bondad - o maldad, según la perspectiva- de políticas de ayuda a refugiados políticos.

\section{El antifascismo en tiempos de la Guerra Civil Española: la revista Futuro}

Uno de los proyectos educativos más ambiciosos emprendidos por Lombardo fue la Universidad Obrera de México, que sirvió además como puerto de acogida para exiliados de orientación izquierdista. Como expresión de su labor editorial, destaca la revista Futuro que, bajo la dirección de Vicente Lombardo, apareció mensualmente entre 1933 y $1946^{26}$. En ella se advierte cómo la oposición de los sectores izquierdistas de México a dos guerras, la civil en España y la mundial, se articuló en torno a un discurso político similar, dirigido en contra «del fascismo de afuera y del fascismo de dentro» ${ }^{27}$. El antifascismo cobró sentido al describir no sólo una realidad europea, sino también local. Al dotar de un sentido más amplio a tópicos como la defensa de la civilización en contra de la barbarie fascista, el antifascismo sirvió en América Latina como un ejercicio de afirmación cultural. Si se trataba, no de una guerra europea, sino de una crisis de la civilización occidental, México podía contribuir con sus esfuerzos y ésta era una responsabilidad que

${ }^{25}$ Gall, 2010: 589-591. En un artículo titulado "Stalin y México. La misión de Lombardo Toledano" publicado bajo la firma de Diego Rivera en mayo de 1938, Trotsky acusó a Lombardo de ser un «estalinista de la última hora» cuyos vínculos con Moscú debían ser vistos con recelo (Trotsky, 2013: 90-94)

${ }^{26}$ No existe todavía un estudio detallado sobre la historia de la Universidad Obrera, aunque una descripción de su oferta educativa puede verse en: $<$ http://www.uom.edu.mx/trabajadores/71_DelaParra.html>.

${ }^{27}$ Unidad contra el fascismo [discurso pronunciado como presidente de la Confederación de Trabajadores de América Latina], 07-VII-1941, por Lombardo Toledano, FHVLT, leg. 422, id. 23638. 
-al menos en el papel- informaría la política de asilo y el apoyo a la causa de los Aliados. Este aspecto se vio fortalecido por el hecho de que muchos de los exiliados europeos antifascistas llevaron a cabo su propio redescubrimiento de México. Cabe mencionar que Futuro sirvió también como un foro para intelectuales cuya solidaridad con España (o repudio del fascismo) no necesariamente los acercaba a posiciones comunistas, como Octavio Paz y Alfonso Reyes.

En el número de Futuro correspondiente a octubre de 1936, un manifiesto firmado por intelectuales asociados a la Universidad Obrera y figuras centrales de la diplomacia mexicana, como Genaro Estrada y Gilberto Bosques, enfatizó la identidad que existía entre la causa de la República Española, la Revolución Mexicana y la «verdadera civilización» ${ }^{28}$. En aras de hacer asequible la causa española para una audiencia mexicana, los firmantes insistían que también México había tenido que vencer obstáculos similares a los de España: la oposición de sus «clases feudales» al progreso y la reforma agraria, una «crisis dolorosa de insurrección militar» y las calumnias del «conservadurismo internacional». En el caso actual, alertaban contra aquellos que condenando la «opresión comunista» supuestamente llevada a cabo en la República, no hacían sino abrir el camino al fascismo. En términos más generales, la guerra civil española fue descrita como un «ensayo sangriento de la próxima e inevitable guerra mundial», la cual enfrentaría a «los esclavistas endiosadores de la fuerza» con los defensores del «patrimonio espiritual de las naciones cultas de Occidente». En otro artículo, el comunista cubano Juan Marinello, entonces exiliado en México, elevó la discusión sobre la República española al plano del imperialismo y el colonialismo: ¿Cómo no entender la simpatía del proletariado hispanoamericano por la España republicana si el parecido entre el «grupo fascista español» y el «grupo dominador» de América Latina llegaba a ser íntimo? ${ }^{29}$ Para Lombardo, la lucha del proletariado español en contra de un «gobierno latifundista y clerical» constituía un ejemplo para las naciones latinoamericanas, incluyendo a México, todavía «un país semicolonial con supervivencias feudales $»^{30}$.

28 AA.VV., 1936: 18-19.

29 Marinello, 1936: 31-32.

${ }^{30}$ Nuevo mensaje al proletariado español, 6 de noviembre de 1936 y ¿Puede ser considerado México como el molde revolucionario para todos los países de la América Latina? Respuesta a un estudio del doctor Nicolás Repetto, líder del Partido Socialista de la Argentina, mayo 1937, FHVLT, leg. 285, id. 16742 y leg. 294, id. 17130. 
Ilustración 2. Gonzalo Paz Pérez, Fascismo sobre México

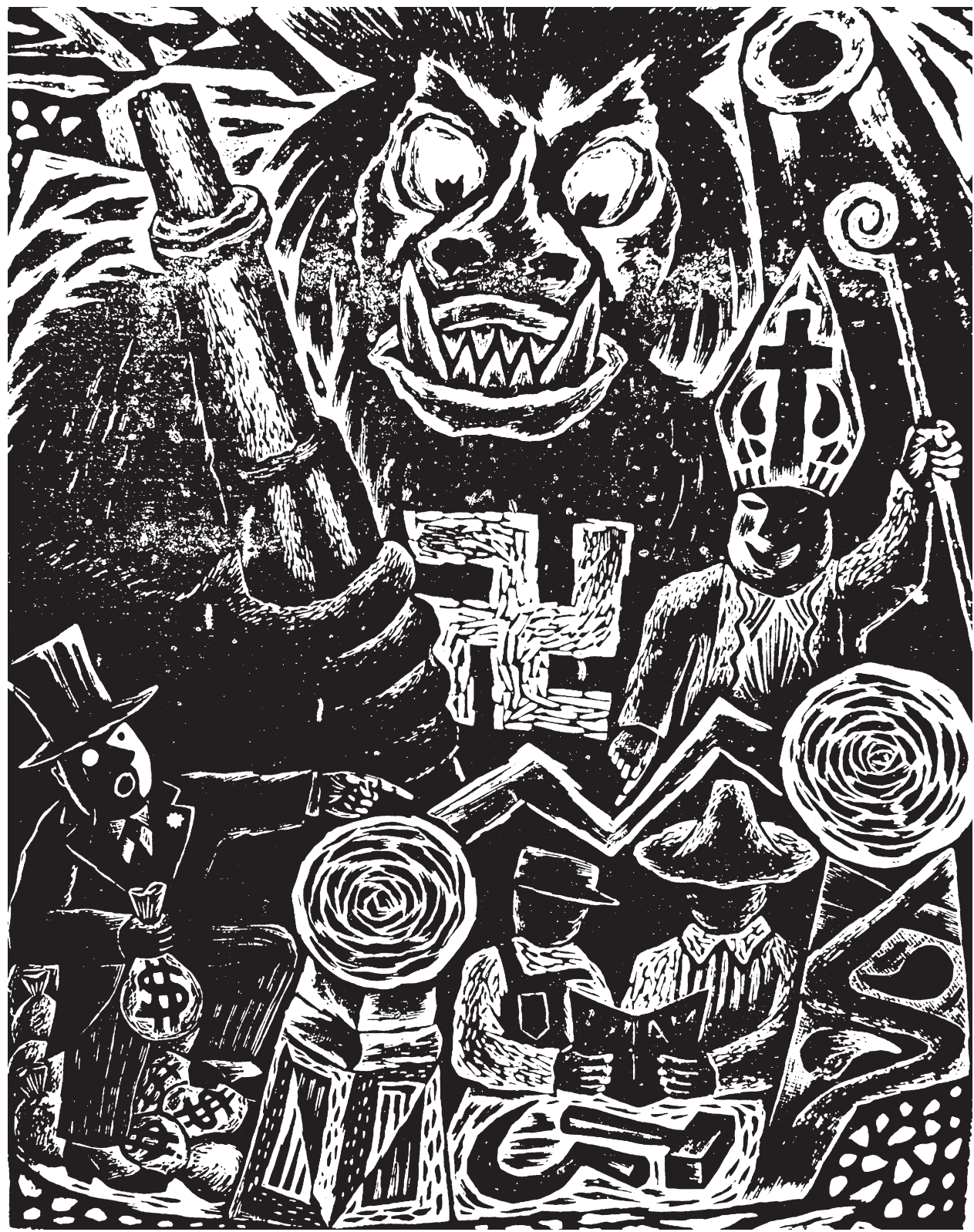

Fuente: Futuro, $3^{\text {a }}$ época/22 (México, diciembre de 1937). 
Usando argumentos similares, Narciso Bassols se valió del fascismo para denunciar la falta de autonomía económica de América Latina, así como el poder desmedido de sus oligarquías. Bassols, secretario progresista de Educación Pública (1931-1934) y representante de México en la Liga de las Naciones (1935) cuando México fue uno de los pocos países en protestar cuando Mussolini invadió Etiopía, fue luego representante diplomático en Francia y pieza clave al organizar la acogida de exiliados republicanos en México. A principios de 1937, Bassols hizo hincapié en cómo España y América Latina se hallaban envueltos en la misma lucha (de clases). También alertó sobre la alianza que se había establecido entre el «reaccionarismo latinoamericano» y el fascismo internacional: mientras que éste satisfacía sus exigencias de mercados y materias primas, aquél encontraba un aliado en su lucha contra el "peligro comunista», como era llamado cualquier intento de rectificar las injusticias sociales inherentes a los «países coloniales o semicoloniales» de América Latina ${ }^{31}$. Por su parte, Ricardo J. Zevada señaló cómo el fascismo había contribuido a dar un aire de «respetabilidad» a los dictadores latinoamericanos: «ya no son generalitos de cuartelazo, ahora son 'líderes' de un estado 'corporativo'; 'guías' o 'directores' de un estado 'totalitario'» ${ }^{32}$. Por tanto, los ejemplos más concretos de esta mezcla de represión política doméstica y penetración económica de países fascistas eran Oscar Benavides en el Perú y Getulio Vargas en el Brasil. En particular, Zevada lamentó la represión del movimiento encabezado por el líder comunista Luis Carlos Prestes en 1935. De hecho, la muerte de la madre de éste, acaecida en México en 1943, se convirtió en excusa para dar una poderosa muestra de apoyo al propio Prestes en la que participaron no sólo Cárdenas y Lombardo, quien hizo un llamado de solidaridad a las agrupaciones obreras, sino también el cónsul de Chile en México, Pablo Neruda ${ }^{33}$.

Respecto al tópico del «fascismo criollo», aplicado al caso de México, Lombardo fue uno de sus exponentes más destacados. En su opinión, los «enemigos de la revolución [mexicana]» no sólo eran necesariamente fascistas que bloqueaban la transformación del país, sino también imperialistas que estaban dispuestos a entregarse al extranjero. Este argumento se remontaba a mediados del siglo XIX, cuando los conservadores mexicanos se habían valido de la intervención de Francia para convertir a Maximiliano de Habsburgo en emperador de México ${ }^{34}$. Para Lombardo, la nación que proponía la

\footnotetext{
31 Bassols, 1937: 28-30.

32 Zevada, 1938: 11.

${ }_{33}$ Crespo, 2012: 11-12.

${ }^{34}$ Lombardo Toledano, 1938: 13.
} 
derecha mexicana era una nación falsificada y, además, en alianza con elementos extranjeros. Ello remite a la interpretación de la Guerra Civil española prevaleciente en círculos comunistas: más que conflicto fratricida, se trataba de una guerra en contra de un invasor extranjero, auxiliado por las clases pudientes locales e incluso por el clero, cuya lealtad pertenecía a Roma ${ }^{35}$. A este repudio al elemento extranjero, se sumaba el patriotismo -contrario al nacionalismo de la derecha fascista- y un espíritu de solidaridad con otros pueblos oprimidos por el fascismo, lo cual conducía a un tópico clásicamente latinoamericano: la lucha en contra del imperialismo. Por ejemplo, José Alvarado criticó que los grupos conservadores en México hicieran alarde de anti-imperialismo al rechazar a la «cultura yanqui», la cual atentaba en contra de las «raíces latinas y españolas» de la cultura del país, obviando el hecho de que «la verdadera lucha antiimperialista tiene fundamentalmente un sentido de liberación económica» ${ }^{36}$.

Éste es un breve esbozo de los discursos políticos - dado el vínculo estrecho entre persuasión y movilización- a partir de los cuales se articuló el apoyo material de la CTM y las fuerzas de izquierda a la política de Cárdenas respecto a la España republicana, la cual incluyó su defensa en foros internacionales y la acogida de casi veinte mil exiliados tras su derrota ${ }^{37}$. El apoyo a la República Española fue interpretado, por Lombardo e intelectuales cercanos a éste, como una manera de apuntalar el programa revolucionario de México. Para ilustrar la fuerza del movimiento obrero, resulta interesante traer a colación un artículo que apareció en el New York Times con motivo del desfile del 1 de mayo de 1939 en la Ciudad de México ${ }^{38}$. El corresponsal norteamericano se refirió al desfile de 70,000 hombres y mujeres frente al Palacio Nacional, durante 3 horas y 14 minutos, como una «demostración de fuerza» del movimiento obrero, dando la impresión de ser «un ejército bien disciplinado, al que sólo le faltaban las armas». Consignó también la presencia de pancartas antifascistas, así como el hecho de que las ventanas de un comercio alemán se hubieran apedreado al grito de «¡Abajo Hitler!». La conclusión del corresponsal era que Lombardo había aprendido bien la lección recientemente dada por el ministro socialista Indalecio Prieto, según el cual el gran error de los «gobiernistas españoles» había sido no dar instrucción militar a los sindicatos

35 Núñez y Faraldo, 2009: 403.

36 Alvarado, 1940: 21.

37 Pla, 2010: 615.

${ }^{38}$ En el FHVLT (leg. 351, id. 19880) hay una traducción al español del artículo original de Raymond Daniell, "Workers' Militia Parades in Mexico: Drilled and Uniformed Groups Impress Foreign Military Observers in Capital". 


\section{Ilustración 3. Luis Arenal: MéXICO NO SERÁ EsPaÑa}

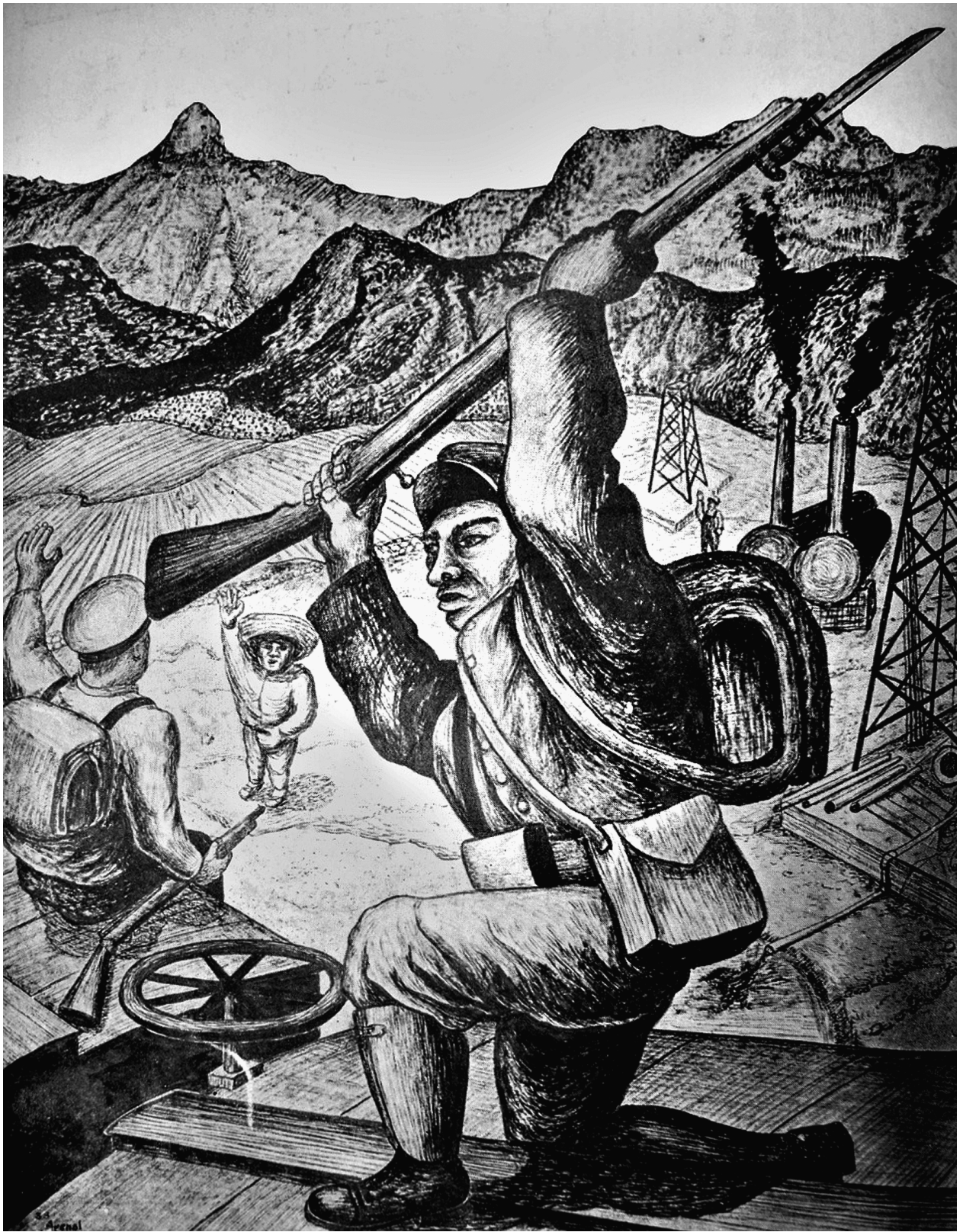

Fuente: Futuro, 3a época/29, México, julio de 1938. 
obreros. En otras palabras, Lombardo quería demostrar que en México no se repetiría lo sucedido en España.

Finalmente, vale la pena dar una mirada hacia los actores que hicieron posible la inmigración española en México. En una carta enviada por Bassols a Lombardo poco después del desfile arriba descrito, destaca la posición comprometida pero realista de aquél, quien asegura: «estoy en la actitud de no cerrar los ojos y empeñarme en enviar millones de españoles por encima de las posibilidades económicas que los mismos españoles tengan y, lo que es también muy importante, por encima y en contra de las reacciones y los límites de la sensibilidad mexicana». Pero sabedor del conflicto desatado entre el presidente del gobierno Negrín y el ministro Prieto, Bassols añadió: «ni a uno ni a otro le debemos dar la oportunidad de hacer en México lo que Fernando VII no se atrevió a hacer: trasladar la capital de España a México» ${ }^{39}$.

\section{El ANTIFASCISMO DURANTE LA GUERRA: LOMBARDO, LA CTAL Y EL EXILIO ALEMÁN}

Al apoyar la candidatura del moderado Manuel Ávila Camacho a la presidencia, es posible que Lázaro Cárdenas tuviera en mente la suerte de la República Española y que, creyendo haber alcanzado la «frontera de lo posible», pusiera un alto a la polarización política en México $^{40}$. Durante la presidencia de Ávila Camacho (1940-1946), el discurso de unidad nacional se tornó en «valor supremo», anteponiéndose al cumplimiento de las promesas revolucionarias y a la continuación del radicalismo en materias agrarias, educativas u obreras ${ }^{41}$. Asimismo, el compromiso de México contra el fascismo fue adquiriendo un nuevo significado: la defensa de la «democracia» se convirtió en la meta principal, mucho más importante que lograr la transformación de la sociedad o de su estructura económica. Ello estuvo relacionado con la creciente influencia de los Aliados, Francia e Inglaterra al principio y Estados Unidos después, en el radio y la prensa mexicanos, en cuanto fueron moldeando las percepciones de la guerra a su favor ${ }^{42}$. En este contexto, marcado por el repliegue del radicalismo y por el acercamiento con Estados Unidos, Lombardo llevó a cabo

39 Carta de Narciso Bassols a Vicente Lombardo Toledano, París, 7-VII-1939, FHVLT, leg. 357, id. 20484.

40 Aboites y Loyo, 2010: 643.

${ }^{41}$ Ibidem: 644.

${ }^{42}$ Schuler, 1998: 147-150. En 1942, luego de haber permanecido prácticamente al margen respecto de la batalla propagandística librada entre el fascismo y el antifascismo, el gobierno mexicano tomó una posición mucho más activa con la creación de una Oficina de Propaganda dentro de la Secretaría de Gobernación. Ésta se proponía enfatizar la defensa de la patria y 
una campaña antifascista como presidente de la Confederación de Trabajadores de América Latina (CTAL) durante la Segunda Guerra Mundial, y colaboró con un aliado estratégico: el exilio antifascista de habla alemana en México.

La CTAL fue resultado del primer (y único) esfuerzo en reunir, en una sola organización obrera latinoamericana y bajo el signo de la heterogeneidad ideológica, prácticamente a todos los movimientos obreros de cada país de América Latina. Fue fundada en 1938 a raíz de una iniciativa de Lombardo, la cual había recibido la venia del presidente Cárdenas ante la urgencia de conseguir todo el apoyo internacional posible para salir adelante con la nacionalización del petróleo ${ }^{43}$. La primera reunión de la CTAL tuvo lugar en la ciudad de México en septiembre de 1938, adonde llegaron delegados de Argentina, Bolivia, Chile, Colombia, Ecuador, Paraguay, Nicaragua, Venezuela y Cuba, más «delegados fraternales» de Francia, Suecia, India y Estados Uni$\operatorname{dos}^{44}$. En sus estatutos se estableció que a la CTAL correspondía encauzar la lucha del proletariado «contra todos los imperialismos [...], contra la guerra de agresión o de conquista, contra la reacción y contra el fascismo ${ }^{45}$. También se emitieron resoluciones en favor del movimiento obrero reprimido por el dictador Anastasio Somoza en Nicaragua, así como en pro de la liberación del líder independentista de Puerto Rico, Pedro Albizu Campos. Tras el estallido de la Segunda Guerra Mundial, la CTAL tomó una posición oficial durante una reunión que tuvo lugar en la Ciudad de México en junio de 1940. Entonces se declaró que al proletariado latinoamericano no le reportaría ningún beneficio entrar en la guerra, un conflicto entre potencias imperialistas, aunque también se hacía un llamado a luchar en contra del fascismo dentro del continente ${ }^{46}$. Ello era un reflejo de fuerzas dentro de la CTAL, con los socialistas como el vicepresidente Francisco Pérez Leirós y el secretario de la región sur José María Argaña (ambos argentinos), que eran generalmente pro-Aliados aunque tenían reticencias respecto de la participación de América Latina en la guerra, predominando sobre los comunistas o pro-comunistas como Lombardo.

La posición de la CTAL cambió radicalmente cuando Alemania invadió a la Unión Soviética. En el primer congreso de la CTAL (Ciudad de México, noviembre de 1941), Lombardo insistió en que era preciso emplear todos los

\footnotetext{
de la unidad nacional, así como promover un sentimiento de solidaridad con Estados Unidos. Rankin, 2009: 112, 120-125.

${ }^{43}$ Alexander, 2009: 57-58.

${ }^{44}$ La presencia de los delegados al Congreso de la CTAL, así como a un Congreso Internacional por la Paz que tuvo lugar en la misma época, se celebró con un mitin en la Plaza de Toros "El Toreo" (Discursos del 11 de septiembre 1938, FHVLT, leg. 329, id. 18659).

4550 Aniversario, 1988: 34.

${ }^{46}$ Alexander, 2009: 64-67.
} 
medios posibles, morales y materiales, para evitar el triunfo del fascismo en Europa. El leitmotiv de Lombardo fue que la lucha contra el fascismo era idéntica a la lucha en pro de la auto-determinación, no sólo de los países sojuzgados por Hitler, sino también de los países latinoamericanos, puesto que se trataba de una lucha universal en contra de la tiranía y la violencia. Pero, dirigiéndose a una audiencia latinoamericana, ¿cómo conciliar esta vertiente anti-imperialista del antifascismo con el apoyo a los Aliados que, poco más tarde, incluirían a Estados Unidos? Aunque su opinión cambiaría con el tiempo, Lombardo instó a no olvidar que la «casta imperialista» de Estados Unidos explotaba a trabajadores latinoamericanos y estadounidenses por igual ${ }^{47}$. Cuando México ingresó oficialmente a la Segunda Guerra Mundial, en mayo de 1942, Lombardo lanzó una convocatoria para la creación de un Comité Nacional de Lucha contra el Nazifascismo, invitando a participar a «todos los ciudadanos, sean liberales, conservadores, socialistas, comunistas, protestantes, católicos o agraristas $\rangle^{48}$. ¿Cuáles eran las ventajas que le proporcionaría a México participar en la batalla contra el Eje? Según Lombardo, el país ganaría el derecho a participar en la «planificación de la post-guerra». Si bien permanecía la idea de que el antifascismo colocaba a México en la vanguardia revolucionaria, los motivos eran menos sospechosos, ahora que se trataba de ponerse «al servicio de la causa de las democracias, que es la propia causa de México». Cabe añadir que Lombardo era partidario de la formación de una brigada de voluntarios latinoamericanos, con cinco mil hombres por país ${ }^{49}$.

Lombardo, en cuanto líder del movimiento antifascista mexicano y latinoamericano, fue un aliado fundamental para las actividades de las organizaciones políticas ligadas al exilio antifascista europeo. Ya desde el sexenio de Cárdenas se había comenzado a dar asilo a exiliados políticos germanohablantes que, en su mayoría, eran comunistas y habían tenido algún vínculo con la Guerra Civil Española. Se calcula que llegaron a México un centenar de éstos, entre ellos: escritores, activistas políticos y periodistas (Anna Seghers, László Radványi, Egon Erwin Kisch, André Simone, Bodo Uhse y Ludwig Renn), funcionarios del Partido Comunista (Paul Merker y Alexander Abusch) y figuras destacadas en el campo de la cultura (Gertrude Duby, antropóloga, y Paul Westheim, historiador del arte). Su filiación política los convertía en huéspedes problemáticos no sólo en la Europa ocupada por el fascismo, sino

47 Lucha contra el nazi-fascismo al interior de los países latinoamericanos, 5-XI-1941, FHVLT, leg. 435, id. 25141.

${ }_{48}$ Declaración de principios, junio de 1942, FHVLT, leg. 487, id. 29437.

49 Aportación del contingente de sangre latinoamericana, 1942, FHVLT, leg. 535, id. 32419 . 
Ilustración 4. La prensa argentina sobre la entrada de MÉXICO a la GUerRa

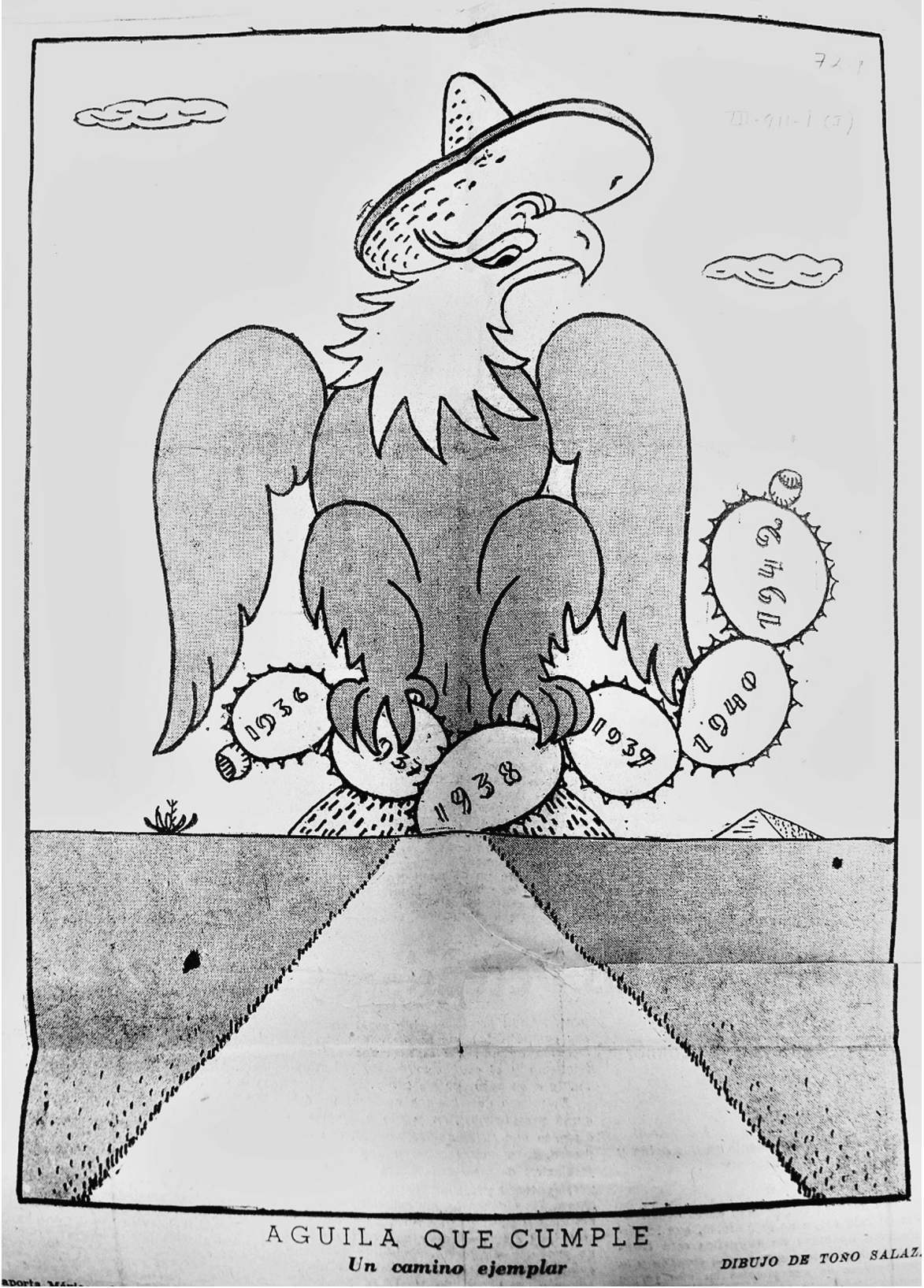

Fuente: Crítica, Buenos Aires, 4-VI-1942. 
también en Estados Unidos y otros países occidentales. Por tanto, la respuesta positiva del gobierno de México fue excepcional, por más que éste adoptara una actitud pasiva al respecto, ya que más que ofrecer abiertamente el refugio se respondía a solicitudes individuales ${ }^{50}$.

Las gestiones fueron facilitadas por varias organizaciones: desde el exterior, la League of American Writers, una asociación de escritores de izquierda que tenía vínculos con el Partido Comunista de Estados Unidos; desde el interior, la Liga Pro Cultura Alemana, en cooperación con el Comité Central Israelita local y, a partir de 1942, el movimiento «Alemania Libre» (Bewegung Freies Deutschland). Conforme fueron llegando más exiliados, hubo una reconfiguración de fuerzas al seno de las propias organizaciones alemanas, puesto que los comunistas boicotearon a la propia Liga, acusándola de tener tendencias trostskistas y anti-soviéticas ${ }^{51}$. Recurrir a la intercesión de Lombardo se convirtió en paso indispensable para saltar las vallas burocráticas y conseguir visados o empleos. En su correspondencia pueden verse peticiones de diversas organizaciones: Alianza Internacional Giuseppe Garibaldi, Acción Republicana Austriaca y la Federación de Organismos de Ayuda a la República Española, entre otras ${ }^{52}$. En la redacción de estas peticiones, se empleó un criterio de utilidad para dar acogida a ciertos individuos, atenuando su filiación política: nunca se habla de comunistas sino de «demócratas sinceros» o «antifascistas buenos y aprobados». En un memorándum de asuntos a discutir con el presidente Ávila Camacho, Lombardo se refirió a la conveniencia de que México aproveche a individuos destacados en la «lucha por la libertad de los pueblos europeos», mientras que en una carta dirigida al secretario de Gobernación, Miguel Alemán, solicita su «ayuda a esta obra de salvación de elementos útiles de las garras del totalitarismo nazi $\rangle^{53}$.

${ }^{50}$ Pohle, 1986: 5, 69; Gleizer, 2010: 658.

51 Mentz et al., 1984: 49-50. Lombardo negó haber preferido a los comunistas de «Alemania Libre», aunque reconoció: «ellos están mucho más cerca de mí porque han buscado mi ayuda para salvar la vida a muchos otros antifascistas europeos y además porque han prestado valiosísimos servicios a la Universidad Obrera de México», Carta de VLT a Enrique Gutmann, 13-VIII-1942, FHVLT, leg. 469, id. 27756.

52 En el caso específico del exilio de habla alemana, en el FHVLT: Carta de Bodo Uhse a VLT, Ciudad de México, 22-XI-1940, leg. 401, id. 22522 y 10-XI-1941, leg. 414, id. 23101; Carta de Acción Republicana Austriaca a VLT, Ciudad de México, 5-VIII-1942, leg. 468, id. 27541; y Carta de la Asociación Pro-Refugiados Políticos de Habla Alemana a VLT, 4-I-1943, leg. 492, id. 29239.

${ }_{53}$ Asuntos para tratar con el C. Presidente de la República, 10-X-1941, FHVLT, leg. 432, id. 24573; Carta de VLT a Miguel Alemán, Ciudad de México, 11-VII-1942, FHVLT, leg. 464, id. 27207. 
Hubo una coincidencia notable entre la manera en que las organizaciones del exilio alemán en México y el propio Lombardo abordaron el tema del antisemitismo y, más concretamente, del Holocausto. En 1938, una de las campañas de propaganda más agresivas llevadas a cabo por la Liga Pro Cultura Alemana consistió en la distribución de carteles por la capital donde se decía que el gobierno nazi consideraba a los mexicanos como raza de segunda clase, basándose en un caso verídico ${ }^{54}$. Ello levantó una protesta airada por parte del ministro de Alemania en México quien argumentó, entre otras cosas, que la amistad de Hitler con el emperador de Japón probaba que «la purificación de la propia raza como suprema ley alemana» era compatible con la estimación de otras razas ${ }^{55}$. Otro evento cultural que despertó el rechazo del ministro alemán fue la serie de conferencias anti-nazis organizadas por la Liga Pro Cultura Alemana en el otoño de 1938, apoyadas abiertamente por la Secretaría de Educación Pública ${ }^{56}$. En esa ocasión, el Taller de Gráfica Popular preparó una serie de carteles para anunciar las conferencias, impresos en tiradas de 2000 ejemplares y pegados en las paredes de la ciudad de México ${ }^{57}$. El Taller de Gráfica Popular se había fundado en 1937, sobre todo a instancias de Leopoldo Méndez, también director del Departamento de Cultura Estética y Periodismo de la Universidad Obrera. Según sus estatutos, el Taller se comprometía a trabajar en pro de los intereses democráticos y progresistas del pueblo de México, auxiliándolo en su lucha en contra de la amenaza fascista ${ }^{58}$.

Más tarde, una vez que "Alemania Libre» sustituyera a la Liga como el núcleo más importante del exilio alemán, el tema del antisemitismo volvió a ser un motivo para unir esfuerzos entre refugiados y círculos izquierdistas locales. El 20 de agosto de 1942, Lombardo Toledano pronunció un discurso en un mitin multitudinario, publicado luego con el título de "Judíos y mexicanos, ¿razas inferiores?”, donde trazó un paralelismo histórico entre las persecuciones contra los judíos y los sufrimientos de los pueblos autóctonos de América.

${ }^{54}$ La Organización para el Extranjero (Auslandsorganisation) del Partido Nacionalsocialista había determinado el origen no ario de los hijos de un alemán casado con una mexicana, a menos de que ésta probara tener pura sangre española (esto es, sin mezcla o Blutsbeimischung con indígenas) por lo menos desde 1800 (Pohle, 1986: 96, 465-467). En el documento hecho público por la Liga, nombre y fechas fueron borrados para evitar represalias.

${ }_{55}$ Carta de Rüdt von Collenberg a Eduardo Hay [Secretario de Relaciones Exteriores], Ciudad de México, 13-X-1938, Archivo de la Secretaría de Relaciones Exteriores, México DF (ASRE), Departamento Diplomático, III-1703-8.

${ }_{56}$ Radkau, 1988: 174. Rankin, 2009: 44-52. Carta del ministro Rüdt von Collenberg al Secretario de Relaciones Exteriores, Eduardo Hay, 14-IX-1938, ASRE, III-1703-8.

57 Caplow, 2007: 135.

58 Ibidem: 123, 132. Las imágenes provienen de Meyer, 1949. 
Ilustración 5. Ilustración de José Chávez Morado para la CONFEREnCia de Ricardo J. Zevada "El fascismo en Latino-América" organizada por la Liga Pro-Cultura Alemana en MéXico (1938)

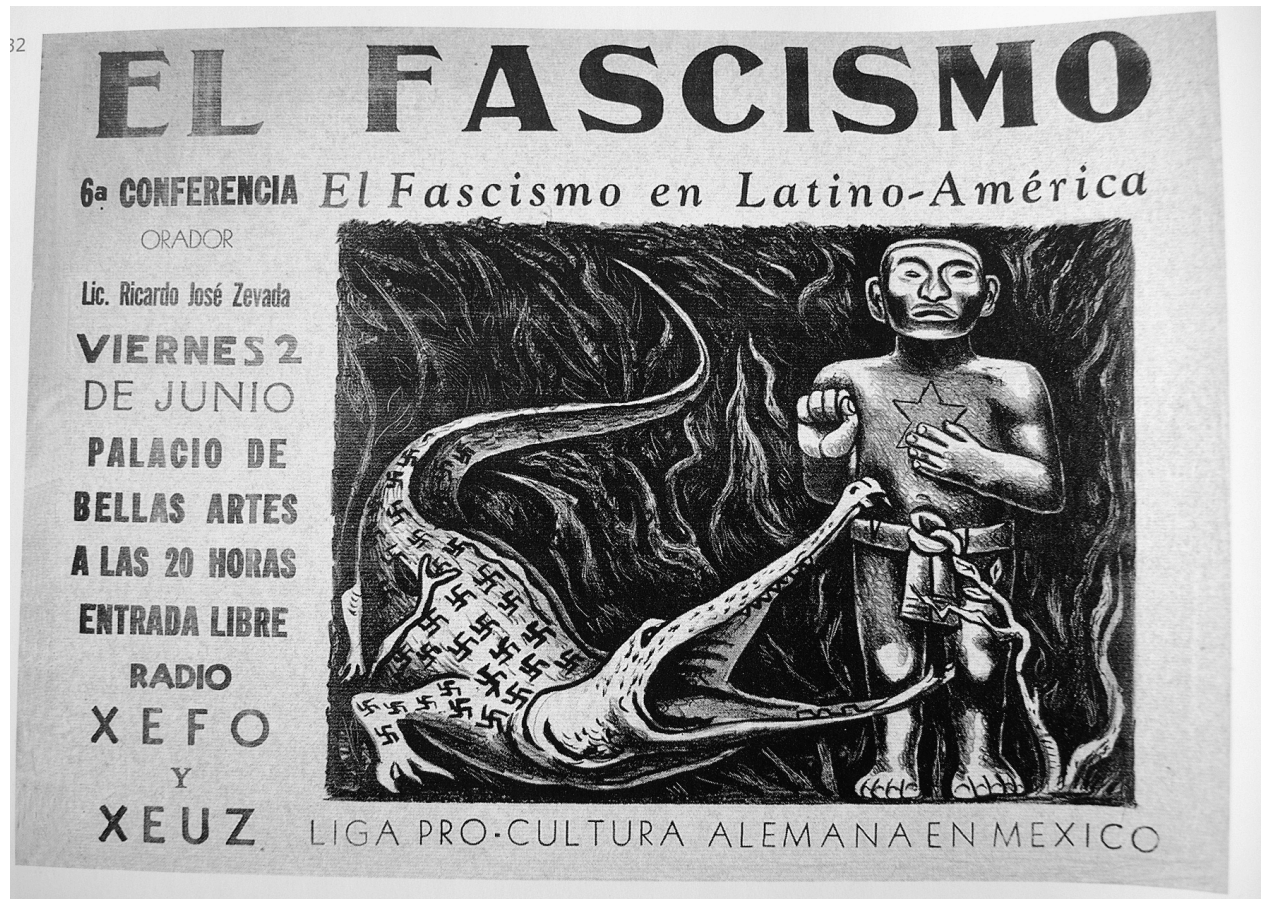

Los mexicanos, según Lombardo, podían comprender la trágica situación de los judíos, puesto que «al nacer, si pudiera aplicarse retrospectivamente la doctrina racial del fascismo, vinimos al mundo degradados» ${ }^{59}$. Para explicar el surgimiento del virulento antisemitismo actual, Lombardo señaló cómo una serie de pensadores judíos habían llevado a cabo un cambio fundamental -que para muchos resultaba problemático o inaceptable- en la manera de concebir a la civilización occidental: en primer lugar, Marx había mostrado que los cambios históricos, lejos de obedecer a un plan divino, se debían principalmente al desarrollo de la economía. Por su parte, tanto Bergson como Freud habían cuestionado el «mito de la omnipotencia de la razón», reivindicando en cambio el papel que la intuición y las fuerzas inconscientes desempeñaban en el comportamiento del hombre. Por último, minando más certezas añejas,

\footnotetext{
${ }^{59}$ Lombardo Toledano, 1942: 26.
} 
ILUSTRACIÓN 6. ILUSTRACIÓN DE ISIDORO OCAMPO PARA LA CONFERENCIA DEL Prof. Enrique Beltrán "El antisemitismo como arma del Fascismo" organizada por la Liga Pro-Cultura Alemana en México (1938)

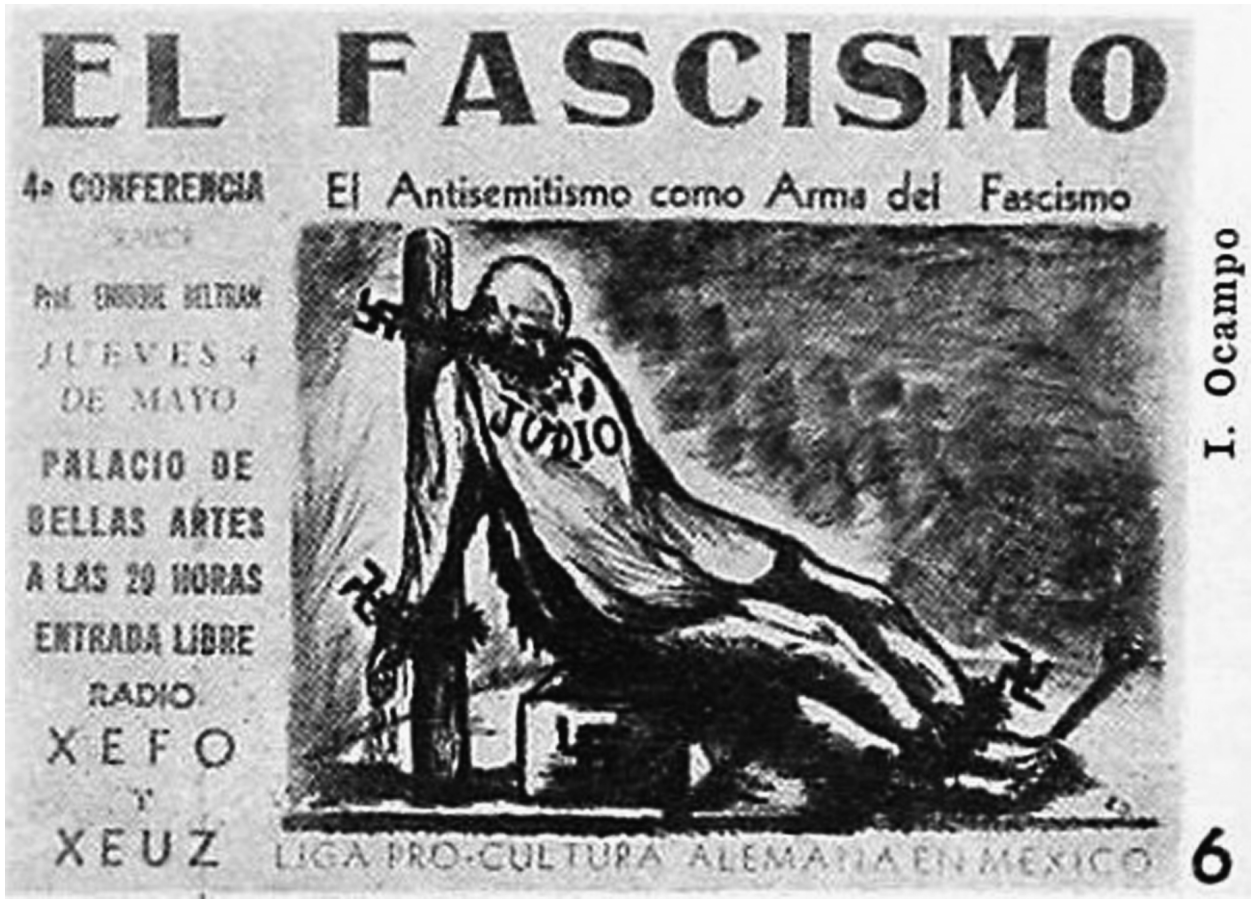

Einstein había revolucionado la concepción del tiempo y el espacio ${ }^{60}$. Pocos años después, el texto de Lombardo fue descrito por un intelectual chileno como «la mejor exposición que se haya hecho por gente de nuestra América acerca del antisemitismo», instando también a sus connacionales a incluir a los mapuches entre las razas injustamente menospreciadas ${ }^{61}$.

No obstante, quizás el mayor esfuerzo realizado por Lombardo para crear conciencia acerca del holocausto del pueblo judío fue un telegrama, enviado en diciembre de 1942, a todos los grupos sindicales asociados a la CTAL:

${ }^{60}$ Ibidem: 16-18. Estos argumentos no carecen de sofisticación, especialmente comparados con los de un pensador moderno tan lúcido como George Steiner (1971: 40-42), según el cual el pueblo judío produjo tres desarrollos históricos que supusieron un «llamado a la perfección», sometiendo así a la conciencia occidental al «chantaje de la trascendencia»: el monoteísmo, el estricto código moral del cristianismo primitivo y el socialismo mesiánico.

${ }^{61}$ Pinochet, 1945: 140-141. 
Informes fidedignos Washington indican matanza dos millones judíos países ocupados nazifascismo y continuación sistemática ordena Hitler exterminio esa raza procedimientos bárbaros sin precedentes. Como protesta propongo todas agrupaciones trabajadores América Latina realicen paro actividades quince minutos próximo día once a la hora considérese mejor debiendo aprovechar mismo para leer protesta formulará esa directiva ilustrando trabajadores y pueblo general conducta nazifascismo. Agrupaciones trabajadores Estados Unidos realizaron ya acto semejante. Ruégoles informar correo aéreo resultado paro. Fraternalmente. VLT ${ }^{62}$.

En 1943, bajo el patrocinio del presidente Ávila Camacho, salió a la luz en México lo que sería el esfuerzo propagandístico más ambicioso de «Alemania Libre»: los 10 mil ejemplares de El libro negro del terror nazi en Europa: testimonio de escritores y artistas de 16 naciones. Entre los temas que el libro tocaba abiertamente, mediante grabados y fotografías, se encontraba el holocausto del pueblo judío. Por qué México, no obstante su política generosa de asilo respecto del exilio republicano español, hizo tan poco para recibir a los refugiados judíos, en comparación con países como Argentina y Brasil, es otra historia, relacionada al criterio tradicional del gobierno mexicano de favorecer sólo la migración que supuestamente tenía mejores posibilidades de integración ${ }^{63}$. El proyecto de El libro negro nació del empeño y capacidad de convocatoria de destacados exiliados alemanes en México, quienes lograron reunir voces del exilio alemán en Estados Unidos (Thomas Mann y Lion Feuchtwanger), del exilio español en México (Juan Rejano y Antonio Mije) y de la política mexicana como, además de Lombardo, Antonio Castro Leal. El libro negro incluyó ensayos organizados de acuerdo a un país, una región o una problemática; además, su diseño estuvo a cargo de Hannes Meyer, arquitecto suizo y antiguo director de la Bauhaus. Un gran número de las ilustraciones provinieron del Taller de Gráfica Popular, cuya dirección emprendería Meyer (1942-1943; 1946-1949) y luego el periodista y comunista alemán Georg Stibi (1943-1946) ${ }^{64}$. En aquellas dedicadas al Holocausto, destaca su veracidad, dado que la tragedia del pueblo judío apenas comenzaba a conocerse. Una fuente de información valiosa para artistas como Leopoldo Méndez y Pablo O'Higgins fueron los relatos de los refugiados llegados a México, más la prensa de izquierda ${ }^{65}$. Nótese, en el trabajo de Méndez, cómo la estética

${ }^{62}$ Telegrama de la presidencia de la CTAL a la Confederación General del Trabajo, Independencia 2880, Buenos Aires, 5-XII-1942, FHVLT, leg. 483, id. 28836. El contenido fue idéntico en mensajes dirigidos a otros países.

${ }_{63}$ Gleizer, 2010: 670. Bokser, 2006: 379-381.

64 Prignitz-Poda, 2002, 18-20.

${ }^{65}$ Caplow, 2007: 163-164. 


\section{Ilustración 7. Leopoldo Méndez: Deportación a la mUerte en EL LiBRo NEGRO DEL TERROR NAZI EN EUROPA: TESTIMONIO DE ESCRITORES Y ARTISTAS DE 16 NACIONES (1943)}

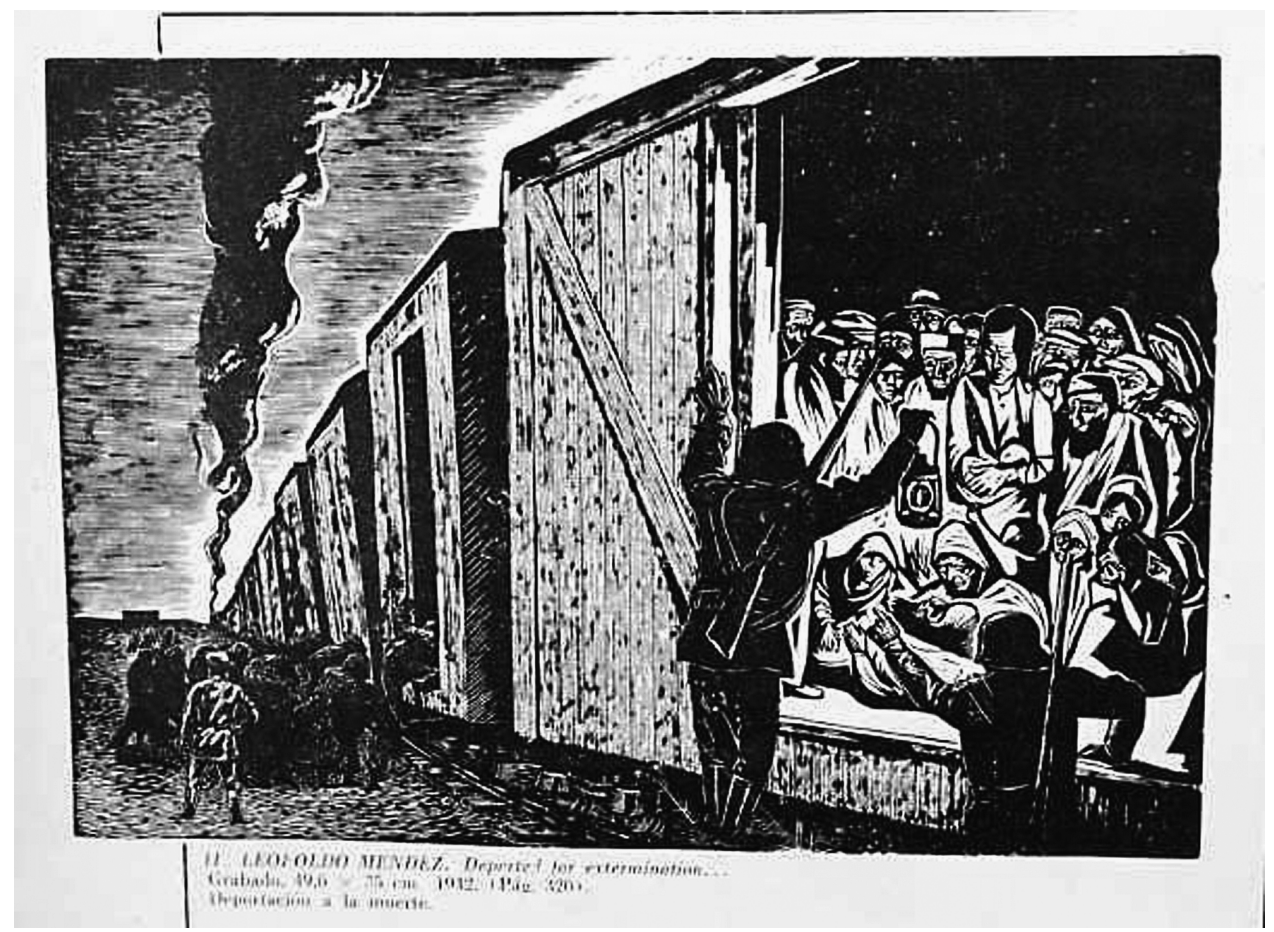

heroica asociada a los ferrocarriles durante la Revolución Mexicana sufre una inversión macabra (ilustración 7).

Uno de los distintivos del exilio germano-hablante en México fue, precisamente, su compromiso con el pueblo judío. Esto se debe a que este exilio vivió en condiciones más libres que otros exilios germano-hablantes, como el de Moscú, bajo la vigilancia de la policía secreta soviética. En las discusiones en torno al Holocausto, según Graf, el exilio germano-hablante en México llegó «hasta las fronteras de las posiciones marxistas tradicionales, aunque rara vez más allá de éstas». En otras palabras, hizo algunas variaciones a un tema comunista: el antisemitismo visto como un instrumento de la burguesía para distraer a la clase obrera respecto de quiénes eran los verdaderos culpables de su opresión, afrimando que éste no era una característica central del régimen de Hitler, empeñado más bien en destruir a la clase obrera y preservar al 
Ilustración 8. Pablo O’Higgins: Trabajo forzado de Judíos en El libro NEGRO DEL TERROR NAZI EN EUROPA: TESTIMONIO DE ESCRITORES $Y$ ARTISTAS DE 16 NACIONES

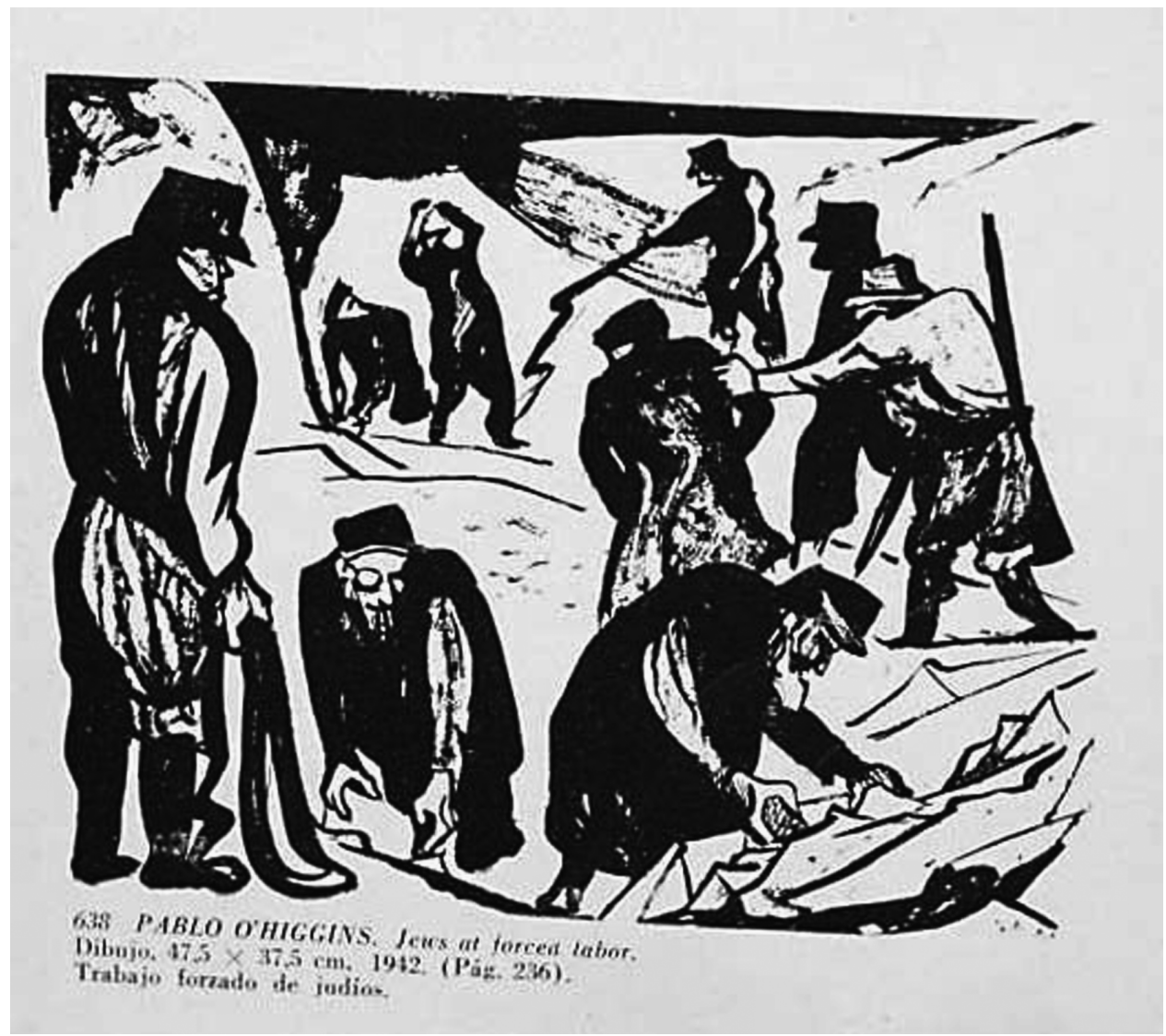

capitalismo ${ }^{66}$. Desde comienzos de 1942, los relatos llegados a México sobre los crímenes cometidos en contra de los judíos se convirtieron en noticia en las páginas del periódico Freies Deutschland. Ahí, Merker insistió en la responsabilidad colectiva del pueblo alemán, apoyando la indemnización de aquellos afectados por el antisemitismo, así como la creación de un estado judío, contando con el apoyo del sindicalismo mexicano. Zuckermann, Simone (alias de Otto Katz) y Kisch establecieron vínculos con los sionistas de habla alemana organizados desde 1943 en el grupo «Hatikva Menorah»; asimismo,

${ }^{66}$ Graf, 2011: 242-243. Herf, 1994: 627-629. 
la colaboración con la logia judía «Spinoza N 1176 de Bené Berith» dio lugar a la publicación de Tribuna Israelita, pro-sionista y pro-soviética, bajo la dirección anónima de Katz ${ }^{67}$. Pero cuando llegó a México la noticia sobre la existencia de campos de exterminio (esto es, no sólo de trabajo forzado), en septiembre de 1944, algunos miembros de Freies Deutschland respondieron de forma ambivalente: por ejemplo, Abusch reconoció haber subestimado el «horror» del régimen nazi, aunque siguió atribuyéndolo a sus ambiciones económicas ${ }^{68}$.

Es preciso aquilatar el argumento de que el exilio germano-hablante en México vivió en una situación «periférica» que, si bien le permitió tomar actitudes poco convencionales, limitó su influencia en el plano internacional ${ }^{69}$. Si bien es indudable que la contribución de México a la Segunda Guerra Mundial fue ante todo simbólica, es cierto también que la cercanía del país con Estados Unidos implicó ventajas importantes. Era relativamente fácil establecer vínculos con el exilio germano-hablante al otro lado de la frontera y ganar así en visibilidad e influencia, pudiendo salir así del supuesto «aislamiento» en el que se encontraban en México. En realidad, dando cuenta de la importancia de sus quehaceres y movimientos, los exiliados alemanes en México fueron vigilados simultáneamente por la Secretaría de Gobernación y el FBI ${ }^{70}$. Por lo demás, dada la posición relativamente destacada que México tenía en América Latina, ya sea por el prestigio de la Revolución, su estabilidad política o su atractivo como refugio para exiliados políticos (también latinoamericanos), la ciudad de México pudo convertirse en plataforma para empresas de más alcance: por ejemplo, Freies Deutschland organizó un Primer Congreso Antifascista en 1943, con delegados de América Latina y, ese mismo año, convocó a la creación de un Comité Latinoamericano de Alemanes Libres ${ }^{71}$. Esta última iniciativa latinoamericana fracasó debido a las divergencias ideológicas con otros grupos antifascistas, comenzando por Das Andere Deutschland de Buenos Aires, movimiento social-demócrata ${ }^{72}$. Al traer a colación el caso de Argentina, es posible meditar por qué los debates de Das Andere Deutschland, en los cuales el Holocausto tuvo un lugar primordial, resultan más realistas y menos dados en el «vacío» que los de Bewegung Freies Deutschland. Una razón importante y que no tiene que ver con periferias políticas o geográficas

\footnotetext{
${ }^{67}$ Pohle, 1989: 66-68.

${ }_{68}$ Graf, 2011: 251-252.

${ }^{69}$ Ibidem: 239-240, 257.

70 Stephan, 2000: 226-232.

${ }^{71}$ Mentz et al., 1984: 52-53.

${ }^{72}$ Friedmann, 2010: 131, 159-163.
} 
es que, a diferencia de Argentina, en México no hubo una constante interacción entre la prensa del exilio y una «prensa étnica» (judía o alemana) bien arraigada, que ejerciera de voz crítica ${ }^{73}$.

Por último, el compromiso del gobierno mexicano con el antifascismo no estuvo exento de fracturas. Un caso interesante y poco conocido es el de la Estación Migratoria de Perote (Veracruz), el más célebre de los centros de internamiento instalado por México, fruto de la colaboración -aunque parcialde México con el programa de deportación de ciudadanos del Eje patrocinado por Estados Unidos. Durante sus tres años de funcionamiento, la estación tuvo una población de cerca de 600 personas: la mayoría eran marinos alemanes e italianos provenientes de los barcos incautados por el gobierno mexicano en abril de 1941, más una pequeña minoría detenida por motivos políticos ${ }^{74}$. Según Inclán, la represión ejercida por el gobierno en contra de nazis o fascistas se hizo de manera arbitraria: mientras que sobornos e influencias siguieron siendo un medio eficaz para escapar del castigo, las acciones tomadas en contra de supuestos fascistas muestran cómo «la violencia del Estado adquirió la forma de negligencia» ${ }^{75}$. Un buen ejemplo fue el encarcelamiento en Perote de un presunto grupo de antifascistas, liderado por Gunther Mahlke. Éste se puso en contacto con Freies Deutschland aunque, debido a la incomunicación, sólo recibió respuesta dos años después, en 1944. Los miembros de Freies Deutschland ofrecieron interceder por ellos, previo interrogatorio para confirmar sus convicciones, el cual nunca tuvo lugar.

\section{EPÍLOGO: EL ANTIFASCISMO EN LA POSGUERRA}

En la posguerra inmediata, la influencia de Lombardo en la política mexicana estaba basada más en su autoridad moral, que en un poder auténtico. Los principios marxistas que le habían inspirado, comenzaban a ser sospechosos en un escenario que comenzaba a anunciar la polarización de la Guerra Fría ${ }^{76}$. Si bien Lombardo persistió en ignorar el totalitarismo que se instalaría en la URSS y en los territorios bajo su influencia, reconfiguró su propio discurso

${ }^{73}$ En México no había un periódico alemán anterior al exilio comparable al Argentinisches Tageblatt (fundado en 1889), ni tampoco una comunidad germano-parlante tan numerosa y arraigada como la argentina. No ignoro, sin embargo, la existencia de publicaciones a cargo de la comunidad judía en México durante los años treinta como Der Weg, Di Tzait (ashkenazitas) u Optimismo (sefardita). Gojman, 2006: 325-329.

74 Inclán Rojas, 2012: 137.

75 Ibidem: 73, 167-172, 179.

76 Bernal Tavares, 1994: 156. 
y advirtió, de cara a la paranoia anticomunista de Estados Unidos, que «el fascismo no es más que [...] la fuerza más agresiva del imperialismo en cualquier país de la tierra y [...] puede volver a vencer en cualquiera de los países, inclusive en aquellos que tomaron las armas en contra de las potencias del Eje» ${ }^{77}$. En la Conferencia de Chapultepec, una reunión de casi todos los países americanos que tuvo lugar en la ciudad de México entre febrero y marzo de 1945, la CTAL se opuso al Plan Clayton propugnado por los delegados de EUA, en el cual se encarecía el libre comercio y las no trabas a la inversión extranjera en América Latina, en contra del proteccionismo enarbolado por Lombardo $^{78}$. Más tarde, cuando tuvo lugar la Conferencia de San Francisco que daría lugar a la formación de las Naciones Unidas, entre abril y junio de 1945, Lombardo no fue invitado a formar parte de la delegación oficial de México $^{79}$. Hacía tiempo que la relación de Lombardo con el gobierno de Ávila Camacho venía resquebrajándose. En 1941, un primer signo de este desencuentro había sido la sustitución de Lombardo por Fidel Velázquez como líder de la CTM, la cual se convirtió así en «un organismo más interesado en someter a los obreros y en preservar las prerrogativas políticas de sus líderes» ${ }^{80}$.

La pérdida de influencia de Lombardo en la política mexicana se hizo más aguda con la llegada de Miguel Alemán a la presidencia (1946-1952). Para el nuevo gobierno, las prioridades fueron la industrialización y el acercamiento a Estados Unidos, inaugurando así una etapa en que los beneficios del crecimiento económico atenuarían temporalmente las preocupaciones acerca de la precariedad democrática del país. A tono con la Guerra Fría, el gobierno de Alemán tomó distancias respecto de lo que quedaba del cardenismo, eliminando resistencias tanto dentro de la izquierda como de los sindicatos independientes. Según Niblo, si Ávila Camacho había dado un viraje conservador al programa de la Revolución Mexicana, Alemán llevó a cabo una auténtica contrarrevolución ${ }^{81}$. Durante el gobierno de Alemán, se redujeron drásticamente los subsidios para la Universidad Obrera y El Popular, contribuyendo así a la marginación de Lombardo y sus seguidores ${ }^{82}$. El hecho de que el apoyo económico a Lombardo no cesara por completo demuestra que en el sistema creado por el PRI, según Iber, los subsidios servían también para

77 Ibidem: 158.

78 Alexander, 2009: 71-72.

79 Niblo, 1999: 164-165.

${ }^{80}$ Aboites y Loyo, 2010: 646.

81 Ibidem: 159.

${ }^{82}$ La Universidad Obrera tenía 715 estudiantes en 1936, año de su inauguración. Este número se redujo a un promedio de 500 en la primera mitad de la década de 1940, para seguir decayendo en los años siguientes (Niblo, 1999: 35-37, 224). 
mantener a la disidencia a raya ${ }^{83}$. Además, el gobierno sabía que Lombardo colaboraba con espías soviéticos en México (por ejemplo, facilitándoles el acceso a Estados Unidos) o que recibía dinero de la Unión Soviética para el financiamiento de la $\mathrm{CTAL}^{84}$.

La reacción de Lombardo a su creciente marginación ejemplifica lo que fue el talón de Aquiles de su manera de hacer política, esto es, que la realización de sus objetivos dependiera siempre de una estrecha colaboración con el gobierno. De ahí que, lejos de buscar la confrontación o la acción democrática e independiente, Lombardo recurriera a estrategias indirectas. Por un lado, insistir en que el movimiento obrero debía su lealtad al gobierno, esperando que ésta fuera recompensada en términos materiales; por el otro, usar una retórica anti-imperialista, pro-soviética y anticlerical, aunque empleando una extrema caución al momento de criticar al gobierno o al partido oficial. De ahí que algunos autores vean en Lombardo a un «oportunista de primera línea» y de dudosa sinceridad ideológica ${ }^{85}$, mientras que otros leen su destino - «hacer del compromiso un estilo de vida y un arte»- ${ }^{86}$ como expresión de las incoherencias del México post-revolucionario, donde la dictadura personal de los caudillos en el poder ponía en contradicho al programa democrático de la propia Revolución ${ }^{87}$.

Al quedarse al margen del sistema, mismo que él había contribuido a crear, Lombardo fundó su propio partido político en 1948 -el Partido Popular, luego Partido Popular Socialista- que no logró atraer a la CTM ni sobreponerse al todopoderoso PRI. Por lo demás, El Popular entró en bancarrota en 1961 y la CTAL se disolvió en 1964. El legado de Lombardo, según Carr, sigue siendo extremadamente ambiguo, siendo casi inextricable al del nacionalismo revolucionario, una ideología llena de mitos respecto al potencial progresista de la Revolución Mexicana que, en última instancia, impidió el surgimiento de una izquierda autónoma ${ }^{88}$. Queda pendiente determinar, en un análisis más detallado del papel de Lombardo en las redes del exilio, hasta qué punto pudo el antifascismo impregnar al nacionalismo revolucionario, convirtiendo algunos de sus temas centrales -como el anti-imperialismo y la defensa de la soberanía- en un discurso capaz de dar al país un protagonismo antes inédito.

\footnotetext{
83 Iber, 2013: 12.

84 Ibidem: 14-15.

85 Niblo, 1999: 113.

86 Meyer, 1969: 465.

87 Paz, 1981: 247.

88 Carr, 1994: 349.
} 
Para cerrar el capítulo de la marginación y cambio de vientos políticos, habría que referirse también al destino que corrieron algunos de los exiliados que se comprometieron con la cuestión judía en México: Paul Merker, Leo Zuckermann, André Simone y Alexander Abusch. Las purgas desatadas tras el desencuentro entre Stalin y Tito a partir de 1948, así como el cambio radical de la política de Stalin respecto de Israel, dieron lugar a una ola de limpieza política, ilustrada con la ejecución, el 3 diciembre de 1952, de Rudolf Slánský y otras figuras prominentes del comunismo checo, la mayoría judíos, incluyendo a Katz ${ }^{89}$. Dos días antes, en la República Democrática Alemana, el miembro del comité central del SED (Sozialistische Einheitspartei Deutschlands) Paul Merker había sido arrestado en Berlín, acusado de haber defendido a los judíos porque los capitalistas judíos e imperialistas americanos le habían pagado para eso. Al ser responsable de publicar las opiniones de Merker en la publicación Freies Deutschland, Alexander Abusch fue relevado de sus cargos en el partido. Leo Zuckermann, quien había colaborado con Merker en un proyecto para indemnizar a los supervivientes judíos en 1948, huyó a Berlín occidental en 1953. En el juicio secreto que se le hizo a Merker en 1955, Abusch testificó en su contra para salvar su posición ${ }^{90}$. Tras el ascenso de Khruschev y la consiguiente «desestalinización» parcial de la política soviética, Merker fue liberado en 1956. A diferencia de Abusch, nunca pudo rehabilitarse ni rehacer su carrera.

\section{REFERENCIAS BIBLIOGRÁFICAS}

50 Aniversario de la Confederación de Trabajadores de América Latina, México, Universidad Obrera, 1988.

AA. VV., "México [manifiesto en pro de la República Española]", Futuro, $3^{a}$ época/3 (México, octubre de 1936): 18-19.

Aboites, Luis y Loyo, Engracia, "La construcción del nuevo Estado, 1920-1945”, Eric Velásquez García et al., Nueva Historia General de México, México, El Colegio de México, 2010: 595-651.

Alexander, Robert Jackson, International Labour Organisations and Organised Labour in Latin American and the Caribbean, Santa Bárbara, California, ABC-CLIO, 2009.

\footnotetext{
89 Herf, 1994: 635-639.

${ }^{90}$ Hartewig, 2000: 166-170.
} 
Alvarado, José, “Anti-imperialismo fascista", Futuro, 3 época/54 (México, agosto de 1940): 20-21.

Bassols, Narciso, "México ante España”, Futuro, 3a época/14 (México, abril de 1937): 28-30.

Bernal Tavares, Luis, Vicente Lombardo Toledano y Miguel Alemán: una bifurcación en la revolución, México, UNAM, 1994.

Bokser Liwerant, Judit, "El México de los años treinta: cardenismo, inmigración judía y antisemitismo", Delia Salazar Anaya (coord.), Xenofobia y xenofilia en la historia de México. Siglos XIX y XX. Homenaje a Moisés González Navarro, México, SEGOB-INAH-DGE Ediciones, 2006: 379-416.

Caplow, Deborah, Leopoldo Méndez: Revolutionary Art and the Mexican Print, Austin, University of Texas, 2007.

Cárdenas, Nicolás y Tenorio, Mauricio, "Mexico 1920s-1940s: Revolutionary Government, Reactionary Politics", Stein Ugelvik Larsen (ed.), Fascism Outside Europe. The European Impulse against Domestic Conditions in the Diffusion of Global Fascism, Nueva York, University of Columbia Press, 2011: 593-627.

Carr, Barry, "The Fate of the Vanguard under a Revolutionary State: Marxism's Contribution to the Construction of the Great Arch", Gilbert M. Joseph y Daniel Nugent (eds.), Everyday Forms of State Formation: Revolution and the Negotiation of Rule in Modern Mexico, Durham, Duke University Press, 1994: 326-352.

Crespo, Regina, “Persona non grata? Lombardo Toledano entre los brasileños”, Revista Casa de las Américas, 267 (La Habana, abril-junio 2012): 3-14.

Fernández del Campo, Luis, "La represión del proletariado argentino", Futuro, 3a época/13 (México, marzo de 1937): 26-29.

Friedmann, Germán, Alemanes antinazis en la Argentina, Buenos Aires, Siglo XXI Editores, 2010.

Gall, Olivia, "Trotsky, huésped del general Cárdenas: un asilo contra vientos y mareas nacionales e internacionales", Javier Garciadiego y Emilio Kourí (comps.), Revolución y exilio en la historia de México. Del amor de un historiador a su patria adoptiva: homenaje a Friedrich Katz, México, COLMEX-University of Chicago-Ediciones Era, 2010: 567-601.

Gleizer, Daniela, "Exiliados políticos y refugiados del fascismo en México: experiencias disímiles", Javier Garciadiego y Emilio Kourí (comps.), Revolución y exilio en la historia de México. Del amor de un historiador a su patria adoptiva: homenaje a Friedrich Katz, México, COLMEX-University of Chicago-Ediciones Era, 2010: 645-670.

Gojman de Backal, Alicia, "Ashkenazitas y sefaraditas frente a la xenofobia de los años treinta en México", Delia Salazar Anaya (coord.), Xenofobia y xenofilia en 
la historia de México. Siglos XIX y XX. Homenaje a Moisés González Navarro, México, SEGOB-INAH-DGE Ediciones, 2006: 323-335.

Graf, Philip, "Ante el Holocausto: El exilio comunista germano-parlante en la Ciudad de México, 1941-1946", Giovanni Di Stefano y Michaela Peters (eds.), México como punto de fuga real o imaginario: el exilio europeo en víspera de la Segunda Guerra Mundial, Munich, Meidenbauer, 2011: 239-259.

Groppo, Bruno, "El antifascismo en la cultura política comunista", Massimo Modonesi y Horacio Crespo (coords.), El comunismo: otras miradas desde América Latina, México: UNAM-Centro de Investigaciones Interdisciplinarias en Ciencias y Humanidades, 2007: 93-117.

Hartewig, Karin, Zurückgekehrt. Die Geschichte der Jüdischen Kommunisten in der $D D R$, Colonia, Weimar, Viena, Böhlau Verlag, 2000.

Herf, Jeffrey, "East German Communists and the Jewish Question: The Case of Paul Merker", Journal of Contemporary History, XXIX/4 (Cambridge/Madison, 1994): 627-661.

Iber, Patrick, "Managing Mexico's Cold War: Vicente Lombardo Toledano and the Uses of Political Intelligence", Journal of Iberian and Latin American Research, XIX/1 (Londres, 2013): 11-19.

Inclán Rojas, Carlos, "Perote y los nazis. Las políticas de control y vigilancia del Estado mexicano a los ciudadanos alemanes durante la Segunda Guerra Mundial (1939-1946)", tesis de licenciatura en Historia, México, UNAM, 2012.

Knight, Alan, "Populism and Neo-Populism in Latin America, Especially Mexico", Journal of Latin American Studies, XXX/2 (Cambridge, 1998): 223-248.

Laborde, Hernán, "Méjico y la U.R.S.S”, Orientación, II/79 (Buenos Aires, 29 de diciembre de 1938): 10.

Lombardo Toledano, Vicente, "El asilo de México para León Trotsky y la actitud del proletariado mexicano", Futuro, 3a época/11 (México, enero de 1937): 9-11.

Lombardo Toledano, Vicente, "La C.T.M. Ante la amenaza fascista”, Futuro, 3 época/25, (México, marzo de 1938): 9-14.

Lombardo Toledano, Vicente, "La situación actual" (discurso pronunciado en la Sesión Solemne del Consejo Nacional del Partido de la Revolución Mexicana el 21 de mayo de 1940), Futuro, $3^{\mathrm{a}}$ época/52 (México, junio de 1940): 7-9.

Lombardo Toledano, Vicente, Judíos y mexicanos, ¿razas inferiores?, México, Universidad Obrera, 1942.

Maihold, Günther, "Gesicht und Maske -Realitat und Ideologie der mexikanischen Arbeiter- und Gewerkschaftsbewegung", Helga Prignitz-Poda, Christina Adam, Ulrike Mühlschlegel y Monika Zessnik (eds.), Taller de Gráfica Popular. Plakate 
und Flugblätter zu Arbeiterbewegung und Gewerkschaften in Mexiko 1937-1986, Berlín, Ibero-Amerikanisches Institut-Stiftung Preussischer Kulturbesitz, 2002: 26-35.

Marinello, Juan, "España, problema y destino de América”, Futuro, 3a época/8 (México, octubre de 1936): 31-32.

Mentz, Brígida von, Pérez Montfort, Ricardo y Radkau, Verena, Fascismo y antifascismo en América Latina y México (apuntes históricos), México, Centro de Investigaciones y Estudios Superiores en Antropología Social, 1984.

Meyer, Hannes, Taller de Gráfica Popular. Doce años de obra artística colectiva, México, La Estampa Mexicana, 1949, disponible en línea: < http://www.graphicwitness.org/group/tgp.htm>.

Meyer, Jean, "Reseña de Robert Paul Millon: Mexican Marxist: Vicente Lombardo Toledano. North Carolina University Press, 1966", Historia Mexicana, XVIII/3 (México, 1969): 465-467.

Meyer, Lorenzo, "La desvanecida ruta de la ambición nacional. La tensión histórica entre el proyecto nacional mexicano y su entorno internacional", Blanca Torres y Gustavo Vega (coords.), Los grandes problemas de México. Relaciones Internacionales, México, El Colegio de México, 2010, vol. XII: 45-62.

Niblo, Stephen R., Mexico in the 1940s. Modernity, Politics, and Corruption, Wilmington, Scholarly Resources, 1999.

Núñez Seixas, Xosé Manoel y Faraldo, José María, "The First Great Patriotic War: Spanish Communists and Nationalism, 1936-1939”, Nationalities Papers, XXXVII/4 (Londres, 2009): 401-424.

Pasolini, Ricardo, "El antifascismo como problema: perspectivas historiográficas y miradas locales", Boletín Bibliográfico Electrónico del Programa Buenos Aires de Historia Política, I/2 (Buenos Aires, septiembre de 1998): 44-49.

Paz, Octavio, El laberinto de la soledad. Postdata. Vuelta a el laberinto de la soledad, México, Fondo de Cultura Económica, 1981.

Pérez Montfort, Ricardo, "Notas sobre el falangismo en México (1930-1940)”, Brígida von Mentz, Ricardo Pérez Montfort y Verena Radkau, Fascismo y antifascismo en América Latina y México (apuntes históricos), México, Centro de Investigaciones y Estudios Superiores en Antropología Social, 1984: 61-78.

Pinochet, Tancredo, "Judíos, mexicanos y araucanos", Judaica, XII/141 (Buenos Aires, marzo 1945): 140-141.

Pla Brugat, Dolores, "El exilio republicano en México", Javier Garciadiego y Emilio Kourí (comps.), Revolución y exilio en la historia de México. Del amor de un historiador a su patria adoptiva: homenaje a Friedrich Katz, México, COLMEXUniversity of Chicago-Ediciones Era, 2010: 611-644. 
Pohle, Fritz, Das mexikanische Exil. Ein Beitrag zur Geschichte der politisch-kulturellen Emigration aus Deutschland (1937-1946), Weimar, Metzler Verlag, 1986.

Pohle, Fritz, "Alemania Libre y sionismo. Política de alianza de los exiliados comunistas hacia la emigración judía (México)", Estudios Migratorios Latinoamericanos, IV/11 (Buenos Aires, abril de 1989): 61-68.

Prignitz-Poda, Helga, "Der TGP im Krieg. Hannes Mayer und Georg Stibi als Geschäftsführer der La Estampa Mexicana", Helga Prignitz-Poda, Christina Adam, Ulrike Mühlschlegel y Monika Zessnik (eds.), Taller de Gráfica Popular. Plakate und Flugblätter zu Arbeiterbewegung und Gewerkschaften in Mexiko 1937-1986, Berlín, Ibero-Amerikanisches Institut-Stiftung Preussischer Kulturbesitz, 2002: 12-25.

Rabinbach, Anson, "Introduction. Legacies of Antifascism", New German Critique, LXVII (Durham North Carolina, invierno de 1996): 3-17.

Rabinbach, Anson, "Paris, Capital of Anti-Fascism", Warren Breckman y Martin Jay (eds.), The Modernist Imagination. Intellectual History and Critical Theory, Nueva York, Bergahn, 2009: 183-209.

Radkau, Verena, "Los Nacionalsocialistas en México", Brígida von Mentz, Ricardo Pérez Montfort, Verena Radkau y Daniela Spenser (eds.), Los empresarios alemanes, el Tercer Reich y la oposición de derecha a Cárdenas, México, CIESAS, 1988: 143-92.

Rankin, Monica A., ¡México, la patria! Propaganda and Production during World War II, Lincoln-Londres, University of Nebraska Press, 2009.

Schuler, Friedrich E., Mexico Between Hitler and Roosevelt. Mexican Foreign Relations in the Age of Lázaro Cárdenas, 1934-1940, Albuquerque, New Mexico University Press, 1998.

Spenser, Daniela, "Vicente Lombardo Toledano envuelto en antagonismos internacionales", Izquierdas, III/4 (Santiago de Chile, 2009): 1-20.

Spenser, Daniela, "El viaje de Vicente Lombardo Toledano al mundo del porvenir", Desacatos, 34 (México, 2010): 77-96.

Steiner, George, In Bluebeard's Castle. Notes Towards a Re-definition of Culture, Londres, Faber \& Faber, 1971.

Stephan, Alexander, Communazis. FBI Surveillance of German Emigré Writers, New Haven, Yale University Press, 2000.

Trotsky, León, Escritos latinoamericanos: en México 1937-40, México-Buenos Aires, Ediciones IPS-Instituto del Derecho de Asilo Museo Casa León Trotsky, 2013. Obras escogidas de León Trotsky, 4. 
Vicente Lombardo Toledano. Datos biográficos, México, Universidad Obrera, 1988. Zevada, Ricardo J., "Cómo nos vamos volviendo fascistas", Futuro, $3^{\text {a }}$ época/24 (México, febrero de 1938): 11-15.

Fecha de recepción: 27 de enero de 2014.

Fecha de aceptación: 28 de mayo de 2014.

\section{Antifascism: a space of encounter between exile and national policy. The case of Vicente Lombardo Toledano in Mexico (1936-1945)}

This article puts forward an original interpretation of antifascism, understood as a transatlantic political culture, focusing upon the case of the union leader Vicente Lombardo Toledano. Between the Spanish Civil War and the Second World War, antifascism in Mexico acquired several meanings, centred on the reinvention of the Mexican Revolution's legacy, while benefiting from the collaboration between European antifascist exiles and local left-wing circles. Making use of novel sources, this article vindicates the key role that Mexico was then able to enjoy internationally due to its ideological commitments.

Key words: antifascism; Mexico; Vicente Lombardo Toledano; Second World War; antiSemitism; German exile. 